Article

\title{
Current Perspectives on the Importance of Pathological Features in Prognostication and Guidance of Adjuvant Chemotherapy in Colon Cancer
}

\author{
Kabytto Chen ${ }^{1,2, *(\mathbb{D}) \text {, Henry Wang }}{ }^{1,2}$, Geoffrey Collins ${ }^{1,2} \mathbb{D}$, Emma Hollands ${ }^{1,2}$, Irene Yuen Jing Law ${ }^{2}$ \\ and James Wei Tatt Toh $1,2, *$ (D)
}

1 Discipline of Surgery, Faculty of Medicine and Health, The University of Sydney, Sydney 2145, Australia; henry.wang@health.nsw.gov.au (H.W.); geoffrey.collins@health.nsw.gov.au (G.C.); emma.hollands@health.nsw.gov.au (E.H.)

2 Division of Colorectal Surgery, Department of Surgery, Westmead Hospital, Westmead 2145, Australia; yuenjing.law@health.nsw.gov.au

* Correspondence: kabytto.chen@health.nsw.gov.au (K.C.); james.toh@sydney.edu.au (J.W.T.T.)

Citation: Chen, K.; Wang, H.; Collins, G.; Hollands, E.; Law, I.Y.J.; Toh, J.W.T. Current Perspectives on the Importance of Pathological Features in Prognostication and Guidance of Adjuvant Chemotherapy in Colon Cancer. Curr. Oncol. 2022, 29 , 1370-1389. https://doi.org/10.3390/ curroncol29030116

Received: 10 January 2022

Accepted: 22 February 2022

Published: 23 February 2022

Publisher's Note: MDPI stays neutral with regard to jurisdictional claims in published maps and institutional affiliations.

Copyright: (C) 2022 by the authors. Licensee MDPI, Basel, Switzerland. This article is an open access article distributed under the terms and conditions of the Creative Commons Attribution (CC BY) license (https:// creativecommons.org/licenses/by/ $4.0 /)$.

\begin{abstract}
There is not a clear consensus on which pathological features and biomarkers are important in guiding prognosis and adjuvant therapy in colon cancer. The Pathology in Colon Cancer, Prognosis and Uptake of Adjuvant Therapy (PiCC UP) Australia and New Zealand questionnaire was distributed to colorectal surgeons, medical oncologists and pathologists after institutional board approval. The aim of this study was to understand current specialist attitudes towards pathological features in the prognostication of colon cancer and adjuvant therapy in stage II disease. A 5-scale Likert score was used to assess attitudes towards 23 pathological features for prognosis and 18 features for adjuvant therapy. Data were analysed using a rating scale and graded response model in item response theory (IRT) on STATA (Stata MP, version 15; StataCorp LP). One hundred and sixty-four specialists (45 oncologists, 86 surgeons and 33 pathologists) participated. Based on IRT modelling, the most important pathological features for prognosis in colon cancer were distant metastases, lymph node metastases and liver metastases. Other features seen as important were tumour rupture, involved margin, radial margin, CRM, lymphovascular invasion and grade of differentiation. Size of tumour, location, lymph node ratio and EGFR status were considered less important. The most important features in decision making for adjuvant therapy in stage II colon cancer were tumour rupture, lymphovascular invasion and microsatellite instability. BRAF status, size of tumour, location, tumour budding and tumour infiltrating lymphocytes were factored as lesser importance. Biomarkers such as CDX2, EGFR, KRAS and BRAF status present areas for further research to improve precision oncology. This study provides the most current status on the importance of pathological features in prognostication and recommendations for adjuvant therapy in Australia and New Zealand. Results of this nationwide study may be useful to help in guiding prognosis and adjuvant treatment in colon cancer.
\end{abstract}

Keywords: PiCC UP study; colon cancer; prognosis; survival; pathological features; adjuvant therapy; chemotherapy

\section{Introduction}

Colon cancer is a leading cause of cancer mortality worldwide [1]. It is a malignancy that displays a diverse set of clinicopathological features and outcomes $[2,3]$. Outcomes in colon cancer vary greatly; 5-year survival rates range from $10-90 \%$ depending on stage and other factors [1].

Current prognostication of colon cancer relies mainly on cancer staging defined by the Union for International Cancer Control (UICC) and American Joint Committee on Cancer (AJCC) TNM staging classification [4]. However, there are considerable differences in 
prognosis within patients of the same pathological stage, especially within the intermediate stages of colon cancer (stages II and III) [5,6]. Further risk stratification may be beneficial to identify patients at high risk of recurrence or metastases and to guide prognostication and subsequent cancer management. This is particularly relevant in stage II colon cancer, where prognosis is relatively good. Five year overall survival rates range from $70 \%$ to $85 \%$, and surgery is curative in 75-80\% of cases [5]. Adjuvant chemotherapy shows only an absolute survival benefit of $3-4 \%$ in stage II colon cancer patients, but up to $30 \%$ of this cohort receives adjuvant chemotherapy, which may be also associated with serious side effects that affect quality of life [6,7]. Therefore, a significant number of stage II colon cancer patients may be subjected to the side effects of chemotherapy without much benefit. More research on identifying histological and molecular markers with prognosticative ability is required to identify the high-risk cohort who would benefit from chemotherapy in stage II colon cancer.

Histological features such as tumour budding, perineural invasion, apical lymph node positivity, lymph node yield, lymph node ratio and molecular features such as microsatellite instability (MSI), KRAS, BRAF and CDX2 have been identified in their ability to guide prognostication and optimise adjuvant treatment. However, there is no clear consensus on which pathological features and biomarkers are important in guiding prognosis in colon cancer and adjuvant therapy in stage II colon cancer.

Results from the PiCC Up study were first published by Toh et al. in 2020, which focused on the role of MSI as a biomarker in colon cancer [8]. This present study uses the same dataset from the PiCC Up study previously published [8]. However, the aim of this study was to assess specialist attitudes and evaluate the importance of all the pathological features of colon cancer studied in the PiCC Up study rather than just MSI in guiding prognosis and in decision-making for adjuvant therapy for stage II colon cancer. This study interrogates the views and perspectives of key decision-makers of colon cancer multidisciplinary teams (MDTs) including colorectal surgeons, medical oncologists and gastrointestinal pathologists in Australia and New Zealand.

\section{Materials and Methods}

Data was abstracted from the original Pathology in Colon Cancer, Prognosis and Uptake of Adjuvant Therapy (PiCC UP) Australia and New Zealand study under the terms of the Creative Commons Attribution Licence (CC BY) [8]. Institutional board approval was obtained (5270) AU RED LNR/17/WMEAD/343.

The PiCC UP study was distributed to members of the Colorectal Surgical Society Australia and New Zealand (CSSANZ), Australasian Gastrointestinal Pathology Society (AGPS), and Medical Oncology Group of Australia (MOGA). One hundred and sixty-four specialists (45 oncologists, 86 surgeons and 33 pathologists) responded and participated in the survey. The survey was open for collection of data from October 2018 to January 2019. Participants who completed the questionnaire had specialist qualifications in pathology, medical oncology or colorectal surgery.

Participant attitudes for the following clinicopathological features affecting colon cancer prognostication were assessed using a 5-scale Likert score; distant metastasis; nodal involvement; tumour rupture (pT4); circumferential resection margin (CRM); lymphovascular invasion (LVI); histological grade; perineural invasion (PNI); microsatellite instability (MSI); lymph node yield (LNY); lymph node ratio (LNR); BRAF mutation; tumour location; tumour size; apical lymph node (ALN); tumour budding; KRAS mutation and CDX2 status. The 5-scale Likert score ordinal scale comprised of "not at all" (1), "not really" (2), "neutral" (3), "likely" (4) and "definitely" (5). There was also an "unsure" option.

Attitudes for the above-mentioned features affecting decision making for adjuvant chemotherapy in stage II disease were also assessed using a 5-scale Likert score. The following clinicopathological features were not included as it was not applicable in stage II disease; lymph node ratio (LNR); apical lymph nodes (ALN); distant metastasis and nodal involvement. 
Descriptive statistics and weighted averages were calculated for all pathological features. Data was then analysed using a rating scale and graded response model in item response therapy model (IRT) on STATA (Stata MP, version 15; StataCorp LP, College Station, TX, USA).

As weighted means in an ordinal scale do not provide the best representation of results in this setting, IRT modelling was used to statistically analyse the results of this survey. IRT modelling is commonly used to analyse Likert-type surveys, particularly in psychometric assessments. IRT modelling scales each item based on the responses to each item and the ability of the respondents on the same metric. Thus, IRT scales the responses to the item according to the ability of respondents answering the questionnaire. The relationship between a respondent's answer on an item and the respondent's overall response is incorporated into scaling each individual item. Test Characteristics Curves (TCC) were generated and IRT scores were abstracted after modelling and fit of IRT analysis. In some cases, where there were too many discontinuous regions within the TCC, an IRT score would not be able to be calculated.

The obtained IRT score was then used to stratify clinicopathological features into a system used by the American College of Pathologists [9]. An IRT score of $\geq 4.50$ was classified as Category I; between 4.00 and 4.49 as Category IIa; 3.50 and 3.99 as Category IIlb; 2.50 and 3.49 as Category III; $<2.50$ as Category IV for prognostication. After IRT modelling, the pathological features were ranked in importance according to IRT score.

For determining adjuvant chemotherapy in stage II colon cancer, IRT scores were grouped to identify overall importance specialists placed on the pathological features. A score of $\geq 4.50$ (rounded to 5) was considered to definitely influence decision-making for adjuvant chemotherapy for stage II colon cancer; 3.50-4.49 (rounded to 4) likely; 2.50-3.49 (rounded to 3) neutral; $<2.5$ (rounded to 1-2) not likely to be useful in guiding adjuvant therapy.

A subgroup analysis analysing attitudes within each specialty (surgeons, pathologists and medical oncologists) was performed to detect different priorities each specialty placed on each pathological feature. A mean score and IRT score were calculated, and a KruskalWallis test was used to test the difference between the three groups.

\section{Results}

One hundred and sixty-four specialists (45 oncologists, 86 surgeons and 33 pathologists) participated in the survey. Of the participants, $80.5 \%$ regularly participated in colorectal MDTs. Six advanced trainees (non-specialists) responded to the questionnaire, and were excluded from analysis.

A descriptive overview of specialist opinions on pathological features influencing prognostications is detailed in Table 1 . Highest ranked features included distant metastasis, tumour rupture, lymph node involvement and involved surgical margin. CDX2 status, EGFR status, tumour size, tumour location and lymph node ratio (LNR) were ranked of lowest importance in determining prognosis in colon cancer.

A descriptive overview of specialist opinions on pathological features influencing adjuvant treatment in stage II colon cancer is detailed Table 2. Highest ranked features included tumour rupture, surgical margin involvement, LVI, positive circumferential margin and perineural invasion. CDX2 status, tumour location, tumour size, TILs, KRAS and BRAF status were ranked of lowest importance in determining prognosis in colon cancer.

Pathological features that specialists were most unsure of included CDX2 status, EGFR status, Lymph node ratio, KRAS status, BRAF status and tumour budding. IRT modelling was achieved in 17 pathological features for prognosis, detailed in Table 3. IRT scores ranged from 2.91 to 4.88 . Nine pathological features were classified into grade I level of evidence (IRT score $\geq 4.50$ ), four into grade IIa (IRT score 4.00-4.49), two into grade IIb (IRT score 3.50-3.99) and two into group III (IRT score < 2.50). 
Table 1. Likert score table for specialist responses to whether pathological feature influence prognostication. Adapted from Wiley Cancer Reports-Toh et al. (2020) [8] under the creative commons attribution license (CC BY).

\begin{tabular}{|c|c|c|c|c|c|c|}
\hline Pathological Feature & Not at All & Not Really & Neutral & Likely & Definitely & Don't Know \\
\hline Distant metastases-extra hepatic & $0.00 \%$ & $0.00 \%$ & $0.00 \%$ & $4.41 \%$ & $94.12 \%$ & $1.47 \%$ \\
\hline Tumour rupture (pT4) & $0.00 \%$ & $0.00 \%$ & $1.47 \%$ & $10.29 \%$ & $88.24 \%$ & $0.00 \%$ \\
\hline Involved lymph nodes & $0.00 \%$ & $0.74 \%$ & $0.74 \%$ & $6.62 \%$ & $91.18 \%$ & $0.74 \%$ \\
\hline Distant metastases-liver & $0.74 \%$ & $0.00 \%$ & $0.74 \%$ & $7.35 \%$ & $89.71 \%$ & $1.47 \%$ \\
\hline Involved surgical margin & $0.00 \%$ & $0.00 \%$ & $1.48 \%$ & $10.37 \%$ & $86.67 \%$ & $1.48 \%$ \\
\hline Circumferential resection margin & $0.00 \%$ & $1.47 \%$ & $4.41 \%$ & $14.71 \%$ & $77.94 \%$ & $1.47 \%$ \\
\hline Involved radial margin & $0.00 \%$ & $1.48 \%$ & $4.44 \%$ & $8.15 \%$ & $82.96 \%$ & $2.96 \%$ \\
\hline Lymphovascular invasion & $0.74 \%$ & $0.74 \%$ & $2.22 \%$ & $25.93 \%$ & $69.63 \%$ & $0.74 \%$ \\
\hline Invasion beyond muscularis propria & $0.00 \%$ & $4.44 \%$ & $2.22 \%$ & $28.15 \%$ & $65.19 \%$ & $0.00 \%$ \\
\hline Grade (degree of differentiation) & $1.47 \%$ & $3.68 \%$ & $2.21 \%$ & $27.94 \%$ & $64.71 \%$ & $0.00 \%$ \\
\hline Microsatellite instability (MSI) & $0.00 \%$ & $1.48 \%$ & $6.67 \%$ & $27.41 \%$ & $62.22 \%$ & $2.22 \%$ \\
\hline Perineural invasion (PNI) & $0.75 \%$ & $2.24 \%$ & $6.72 \%$ & $38.81 \%$ & $50.00 \%$ & $1.49 \%$ \\
\hline Lymph node yield (LNY) & $0.00 \%$ & $5.19 \%$ & $11.85 \%$ & $39.26 \%$ & $42.22 \%$ & $1.48 \%$ \\
\hline Apical node status & $0.00 \%$ & $4.44 \%$ & $6.67 \%$ & $40.74 \%$ & $44.44 \%$ & $3.70 \%$ \\
\hline Tumour infiltrating Lymphocytes & $0.73 \%$ & $5.11 \%$ & $11.68 \%$ & $48.18 \%$ & $31.39 \%$ & $2.92 \%$ \\
\hline Tumour budding & $0.74 \%$ & $5.88 \%$ & $11.76 \%$ & $39.71 \%$ & $36.03 \%$ & $5.88 \%$ \\
\hline BRAF status & $0.74 \%$ & $2.22 \%$ & $14.07 \%$ & $29.63 \%$ & $43.70 \%$ & $9.63 \%$ \\
\hline KRAS status & $1.47 \%$ & $5.15 \%$ & $16.91 \%$ & $29.41 \%$ & $36.76 \%$ & $10.29 \%$ \\
\hline Right versus left side & $5.15 \%$ & $17.65 \%$ & $16.18 \%$ & $36.03 \%$ & $23.53 \%$ & $1.47 \%$ \\
\hline Lymph node ratio (LNR) & $0.74 \%$ & $4.41 \%$ & $14.71 \%$ & $34.56 \%$ & $30.88 \%$ & $14.71 \%$ \\
\hline Size of tumour & $5.88 \%$ & $27.21 \%$ & $19.85 \%$ & $31.62 \%$ & $15.44 \%$ & $0.00 \%$ \\
\hline EGFR status & $2.96 \%$ & $8.89 \%$ & $23.70 \%$ & $28.15 \%$ & $18.52 \%$ & $17.78 \%$ \\
\hline CDX2 status & $4.48 \%$ & $9.70 \%$ & $22.39 \%$ & $16.42 \%$ & $5.22 \%$ & $41.79 \%$ \\
\hline
\end{tabular}

Table 2. Likert score table for specialist responses to whether pathological feature influence decisionmaking in guiding adjuvant treatment in stage II colon cancer. Adapted from Wiley Cancer ReportsToh et al. (2020) [8] under the creative commons attribution license (CC BY).

\begin{tabular}{|c|c|c|c|c|c|c|}
\hline Pathological Feature & Not at All & Not Really & Neutral & Likely & Definitely & Don't Know \\
\hline Tumour rupture (pT4) & $0.00 \%$ & $0.74 \%$ & $2.94 \%$ & $30.15 \%$ & $64.71 \%$ & $1.47 \%$ \\
\hline Involved surgical margin & $2.99 \%$ & $2.99 \%$ & $5.97 \%$ & $22.39 \%$ & $64.93 \%$ & $0.75 \%$ \\
\hline Involved radial margin & $3.70 \%$ & $2.96 \%$ & $8.15 \%$ & $22.22 \%$ & $60.74 \%$ & $2.22 \%$ \\
\hline Lymphovascular invasion (LVI) & $1.48 \%$ & $2.22 \%$ & $8.89 \%$ & $45.19 \%$ & $41.48 \%$ & $0.74 \%$ \\
\hline Circumferential resection margin (CRM) & $3.70 \%$ & $8.15 \%$ & $13.33 \%$ & $28.15 \%$ & $45.19 \%$ & $1.48 \%$ \\
\hline Perineural invasion (PNI) & $1.48 \%$ & $11.11 \%$ & $15.56 \%$ & $42.96 \%$ & $27.41 \%$ & $1.48 \%$ \\
\hline Grade (degree of differentiation) & $3.70 \%$ & $8.89 \%$ & $22.22 \%$ & $38.52 \%$ & $23.70 \%$ & $2.96 \%$ \\
\hline Microsatellite instability (MSI) & $5.19 \%$ & $15.56 \%$ & $17.04 \%$ & $25.19 \%$ & $34.07 \%$ & $2.96 \%$ \\
\hline Lymph node yield (LNY) & $5.93 \%$ & $14.81 \%$ & $21.48 \%$ & $34.07 \%$ & $20.00 \%$ & $3.70 \%$ \\
\hline Invasion beyond muscularis propria & $10.53 \%$ & $16.54 \%$ & $19.55 \%$ & $29.32 \%$ & $22.56 \%$ & $1.50 \%$ \\
\hline Tumour budding & $7.41 \%$ & $16.30 \%$ & $21.48 \%$ & $35.56 \%$ & $12.59 \%$ & $6.67 \%$ \\
\hline Tumour infiltrating lymphocytes (TILS) & $8.89 \%$ & $24.44 \%$ & $30.37 \%$ & $24.44 \%$ & $5.93 \%$ & $5.93 \%$ \\
\hline BRAF status & $10.45 \%$ & $13.43 \%$ & $25.37 \%$ & $22.39 \%$ & $14.18 \%$ & $14.18 \%$ \\
\hline KRAS status & $12.69 \%$ & $18.66 \%$ & $25.37 \%$ & $17.16 \%$ & $13.43 \%$ & $12.69 \%$ \\
\hline EGFR status & $13.53 \%$ & $18.05 \%$ & $28.57 \%$ & $15.04 \%$ & $9.02 \%$ & $15.79 \%$ \\
\hline Size of tumour & $24.44 \%$ & $34.07 \%$ & $23.70 \%$ & $11.11 \%$ & $3.70 \%$ & $2.96 \%$ \\
\hline Right versus left colon cancer & $23.13 \%$ & $30.60 \%$ & $29.85 \%$ & $8.21 \%$ & $3.73 \%$ & $4.48 \%$ \\
\hline CDX2 status & $14.39 \%$ & $13.64 \%$ & $29.55 \%$ & $8.33 \%$ & $2.27 \%$ & $31.82 \%$ \\
\hline
\end{tabular}


Table 3. Item Response Theory (IRT) and weighted average scores for pathological features influencing prognosis in colon cancer: Adapted from Wiley Cancer Reports-Toh et al. (2020) [8] under the creative commons attribution license (CC BY).

\begin{tabular}{|c|c|c|c|c|c|c|}
\hline Pathological Features & Grade & $\begin{array}{l}\text { Prognosis } \\
\text { IRT Score }\end{array}$ & $\begin{array}{l}\text { Lower Limit } \\
\text { 95\% C.I. }\end{array}$ & $\begin{array}{l}\text { Upper Limit } \\
95 \% \text { C.I. }\end{array}$ & $\begin{array}{l}\text { Weighted } \\
\text { Average }\end{array}$ & $\begin{array}{l}\text { \% Likely/Definitely to } \\
\text { Influence Prognosis }\end{array}$ \\
\hline Distant Metastases & \multirow{9}{*}{ Grade I } & 4.88 & 4.85 & 4.91 & 4.88 & $98.53 \%$ \\
\hline Lymph Node Metastases & & 4.88 & 4.56 & 4.96 & 4.86 & $97.80 \%$ \\
\hline Tumour Rupture & & 4.87 & 4.78 & 4.93 & 4.87 & $98.53 \%$ \\
\hline Liver Metastases & & 4.85 & 4.45 & 4.95 & 4.81 & $97.06 \%$ \\
\hline Involved Margin & & 4.83 & 4.46 & 4.93 & 4.79 & $97.04 \%$ \\
\hline Radial Margin & & 4.69 & 4.13 & 4.87 & 4.64 & $91.11 \%$ \\
\hline Circumferential Resection Margin & & 4.65 & 4.63 & 4.67 & 4.65 & $92.65 \%$ \\
\hline Lymphovascular Invasion & & 4.64 & 4.28 & 4.78 & 4.61 & $95.56 \%$ \\
\hline Grade of Differentiation & & 4.52 & 4.35 & 4.63 & 4.51 & $92.65 \%$ \\
\hline Microsatellite Instability & \multirow{4}{*}{ Grade IIa } & 4.47 & 4.05 & 4.68 & 4.44 & $89.63 \%$ \\
\hline Perineural Invasion & & 4.35 & 3.77 & 4.59 & 4.31 & $88.81 \%$ \\
\hline BRAF Status & & 4.3 & 0.211 & 4.95 & 3.84 & $73.33 \%$ \\
\hline Lymph Node Yield & & 4.14 & 4.11 & 4.17 & 4.14 & $81.48 \%$ \\
\hline Lymph Node Ratio & \multirow[b]{2}{*}{ Grade IIb } & 3.96 & 0.161 & 4.83 & 3.46 & $65.44 \%$ \\
\hline Location-Right vs. Left & & 3.54 & 2.63 & 4.15 & 3.51 & $59.56 \%$ \\
\hline Size of Tumour & \multirow{2}{*}{ Grade III } & 3.23 & 2.93 & 3.52 & 3.24 & $47.06 \%$ \\
\hline EGFR Status & & 2.97 & 2.58 & 3.31 & 2.97 & $46.67 \%$ \\
\hline
\end{tabular}

IRT modelling was achieved in 10 pathological features for adjuvant therapy, detailed in Table 4. IRT scores ranged from 2.24 to 4.55 . There was a much wider variation in clinician perspectives towards pathological features in determining adjuvant therapy in stage II colon cancer compared to prognostication. Features that were highly ranked included tumour rupture, LVI and MSI-H. A large proportion of clinicians did not believe tumour location or tumour size to be of use in determining adjuvant therapy for stage II colon cancer.

Table 4. Item Response Theory (IRT) and weighted average scores for pathological features influencing decision-making for adjuvant chemotherapy in stage II colon cancer: Adapted from Wiley Cancer Reports-Toh et al. (2020) [8] under the creative commons attribution license (CC BY).

\begin{tabular}{|c|c|c|c|c|c|c|}
\hline Pathological Features & $\begin{array}{l}\text { Adjuvant } \\
\text { Chemotherapy } \\
\text { IRT Score }\end{array}$ & $\begin{array}{c}\text { Lower Limit } \\
95 \% \text { C.I. }\end{array}$ & $\begin{array}{c}\text { Upper Limit } \\
95 \% \text { C.I. }\end{array}$ & $\begin{array}{l}\text { Overall Recom- } \\
\text { mendation }\end{array}$ & $\begin{array}{l}\text { Weighted } \\
\text { Average }\end{array}$ & $\begin{array}{c}\text { \% Likely/Definitively } \\
\text { to Influence Adjuvant } \\
\text { Treatment in Stage II } \\
\text { Colon Cancer }\end{array}$ \\
\hline Tumour Rupture & 4.55 & 4.49 & 4.59 & Definitely & 4.54 & $94.86 \%$ \\
\hline Lymphovascular Invasion & 4.25 & 3.72 & 4.51 & \multirow{2}{*}{ Likely } & 4.21 & $86.67 \%$ \\
\hline Microsatellite Instability & 3.62 & 2.89 & 4.15 & & 3.59 & $59.26 \%$ \\
\hline Lymph Node Yield & 3.36 & 3.14 & 3.56 & \multirow{3}{*}{ Neutral } & 3.36 & $54.07 \%$ \\
\hline Invasion beyond Muscularis Propria & 3.34 & 2.36 & 4.07 & & 3.32 & $51.88 \%$ \\
\hline Tumour Budding & 3.18 & 1.85 & 3.97 & & 3.1 & $48.15 \%$ \\
\hline Tumour Infiltrating Lymphocytes & 2.81 & 1.78 & 3.62 & \multirow{2}{*}{ Neutral } & 2.76 & $30.37 \%$ \\
\hline BRAF Status & 2.78 & 1.52 & 3.76 & & 2.74 & $36.57 \%$ \\
\hline Size of Tumour & 2.25 & 1.77 & 2.81 & \multirow{2}{*}{ Not really } & 2.27 & $14.81 \%$ \\
\hline Location-Right vs. Left & 2.24 & 2.14 & 2.36 & & 2.25 & $11.94 \%$ \\
\hline
\end{tabular}

\section{Discussion}

Understanding molecular and histological pathological features in colon cancer with prognosticative ability may help identify colon cancer patients at higher risk of recurrence or metastasis, allowing more accurate prognostication and guidance with adjuvant therapy. Currently, TNM staging by Union for International Cancer Control (UICC) and American Joint Committee on Cancer (AJCC) TNM is the main driver of prognostication [2,5]. However, there are also histological and molecular markers that may be useful in prognostication and optimisation of adjuvant treatment. Histological features include tumour budding, perineural invasion, apical lymph node positivity, lymph node yield and lymph node ratio. Molecular features include MSI, KRAS, BRAF and CDX2 [3,4,10-14]. Currently, there is no international consensus on their roles, and different international guidelines utilise different pathological features to help with prognostication and decision-making in adjuvant chemotherapy in stage II colon cancer $[5,6]$.

To date, this survey was the largest survey of specialists in Asia Pacific on the attitudes regarding different pathological features in guiding prognosis and adjuvant treatment 
in colon cancer. By comparing current perspectives with current evidence in literature, this study identified that a significant number of specialists were unsure of the role of several biomarkers such as CDX2, EGFR, KRAS and BRAF status on the prognostication of colorectal cancer and its influence on adjuvant therapy in stage II disease. Specialists had more awareness of MSI. We have previously published on the importance of MSI using the PiCC Up data [8] as well as a comprehensive review of the literature on the value of pathological features in guiding prognostication in colorectal cancer [15]. A better understanding of molecular markers and pathological features is important in the move towards precision oncology, with molecular markers and pathological features used to guide prognostication and identification of high-risk stage II colon cancer patients for chemotherapy as well as other management decision-making strategies.

In this discussion, we compare the results of this survey with the evidence in the existing literature, identifying the gaps in knowledge, barriers and limitations of the current evidence as well providing an understanding of where the strength of evidence lies. Features have been grouped together based on the grading system based on IRT scores (see Table 3).

\subsection{Grade 1 Features}

\subsubsection{Distant Metastasis, Lymph Node Metastasis and Tumour Rupture}

In keeping with existing literature, TNM staging was seen as the most important consideration in prognostication of colon cancer by Australian and New Zealand specialists. Presence of distant metastasis, lymph node metastasis and advanced tumour stage obtained highest scores on IRT modelling and all clinicians were aware of its prognosticative significance. The AJCC UICC TNM staging criteria is used widely in international guidelines $[2-4,11,14]$. Distant metastasis and regional nodal involvement are the strongest predictors of poor prognosis $[4,16]$. Distant metastasis confers a $10-15 \% 5$ year survival rate [17]. Nodal involvement also decreases five year survival significantly (30-60\% vs. $70-90 \%$, node positive vs. node negative) $[18,19]$, and chances of cancer recurrence are higher $(30-35 \%)[20,21]$. Similarly, higher T-staging also has a significant negative prognostic effect, being associated with both nodal and metastatic spread. Within T4 tumours, some may also be unresectable, and attempts at resection may lead to R1 or R2 incomplete resections [22].

This study also found tumour rupture (advanced T-stage) to "definitely" influence decision making, in line with international guidelines. The American Society of Clinical Oncology (ASCO), National Comprehensive Cancer network (NCCN), American Society of Colon and Rectal Surgeons (ASCRS), European Society for Medical Oncology (ESMO) and National Health and Medical Research Council (NHMRC) guidelines all identify tumour perforation as a high-risk feature that when considering adjuvant chemotherapy in stage II colon cancer $[3,5,10,12,14]$.

\subsubsection{Circumferential Resection Margin (CRM)}

In this study, Australian and New Zealand specialists identified CRM as an important histological consideration in guiding prognosis and need for adjuvant therapy ranking 5 (of 18) in order of importance in the decision-making for adjuvant therapy. This is similar to international guidelines such as NCCN and ESMO, where CRM positivity represents a pathological feature within its criteria for adjuvant chemotherapy in stage II colon cancer [3,10]. It is included in standardised histological reporting criteria for colorectal cancers [23,24]. CRM greater than $1 \mathrm{~mm}$ is considered negative and is recommended for all resections. CRM positivity may correlate with the quality of surgery performed $[3,10,12,13]$. Occurring in up to $20 \%$ of cases, CRM positivity is associated with advanced stage on initial diagnosis and high-risk histological features such as perineural (PNI) and lymphovascular invasion (LVI). It is a strong indicator of recurrence and reduced survival in colorectal cancers $[25,26]$. 


\subsubsection{Lymphovascular Invasion (LVI)}

LVI is considered a key component in the progression to lymph node metastasis and is well recognised as a poor prognosticator in colon cancer, independent of stage [27-33]. Patients with LVI positivity have an increased risk of overall mortality and a lower diseasefree survival (DFS) [27,30-33]. The AJCC-UICC TNM staging manual currently classifies LVI as a factor in the prognostication of CRC [4], and recommends routine pathological assessment [24]. While Australian guidelines do not specifically identify LVI in determining need for adjuvant therapy, our survey shows an awareness of LVI as a factor in influencing adjuvant therapy in stage II colon cancer among Australian and New Zealand specialists. LVI ranked 8 (of 23) in order of importance for prognostication and 8 (of 17) after IRT modelling.

LVI also ranked second (of 10) in IRT modelling in importance when influencing adjuvant therapy decision making. Specialists in our survey thought LVI was "likely" to affect adjuvant therapy. This is reflective of multiple international guidelines, with LVI included in the definition of "high-risk" stage II colon cancer in the ASCO, NCCN and ESMO guidelines $[3,10,14]$. Adjuvant chemotherapy may have a protective effect in the setting of Stage II colon cancers and LVI positivity, with Gao et al. demonstrating improved 5-year overall survival (OS) $(66.7 \%$ vs. $40.9 \%, p=0.004)$ and DFS rates $(64.1 \%$ vs. $36.3 \% p=0.002$ ) [28]. However, there is also evidence in the literature suggesting that adjuvant chemotherapy may not improve survival in stage II colon cancer patients with high risk factors $[6,34,35]$. Further randomised controlled trials selectively targeting high-risk patients will need to be conducted in the future.

\subsubsection{Histological Grade}

Our study showed that histological grade is likely to be an important marker of prognosis with the majority of specialists indicating that it was likely to influence prognosis in colon cancer. Tumour grade has been consistently reported to be a stage-independent negative prognostic factor in colon cancer [36-39]. It is utilised in most international guidelines and documentation is standard in specimen assessment. The latest edition of the AJCC TNM staging system identifies histological grade as a prognostic factor in colon cancer $[4,23]$. A lack of a standardised system and interobserver variability remains the main limitation in the assessment of tumour grading [36,38,40]. Patients with high grade colon cancer have an increased recurrence risk with a lower DFS and disease specific survival (DSS) compared to those with low grade disease [9,38,39,41,42]. High grade early stage I and II colon cancer may have worse prognosis than low grade stage III disease in terms of DSS [40].

The majority of survey respondents (62\%) also believed that it would influence recommendations for adjuvant therapy. In stage II disease, a high tumour grade is identified as a high-risk factor for recurrence by many international guidelines, with NCCN, ASCO, ESMO, ASCRS, NHMRC and NCI guidelines recommending adjuvant chemotherapy in this subset of patients [3,10-14].

\subsection{Grade IIa Features}

\subsubsection{Perineural Invasion}

A majority of specialists believed that PNI status was likely to influence prognosis in colon cancer (89\%). PNI was ranked similar to MSI status and LVI in this study. In the literature, PNI is considered on par with other established prognostic factors such as tumour grade, T-stage, $\mathrm{N}$-stage, metastasis and extramural invasion [43]. Colon cancer patients with PNI have significantly worse OS, DFS and CSS, independent of cancer stage [43-47]. PNI is identified as an additional tumour related prognostic factor by the latest AJCC-UICC TNM staging criteria [4].

A majority of specialists also believed that PNI status was likely to guide recommendation for the use of adjuvant therapy in stage II disease (70\%). In the literature, several authors have suggested the use of PNI status to facilitate the selection of patients with 
stage II colon cancer for adjuvant chemotherapy [5,6,48,49]. Liebig et al. reported that stage II PNI-positive patients had poorer prognosis compared to stage III PNI-negative patients [45]. Multiple international oncology guidelines (National Comprehensive Cancer Network (NCCN), ASCRS American society of colon and rectal surgeons (ASCRS) and European Society for Medical Oncology (ESMO)) utilise perineural invasion as a risk factor for recurrence and recommend consideration of adjuvant chemotherapy in this subset of patients $[3,5,10]$.

\subsubsection{Microsatellite Instability (MSI)}

The role of MSI in colon cancer by the PiCC Up study has been explored in an earlier study by Toh et al. (2020) [8]. MSI was highlighted as an important biomarker in prognostication in this study. It was ranked more important than KRAS, BRAF and CDX2 and was ranked similar to LVI and PNI. MSI-H has been shown to convey a better prognosis in early stage CRC [50-52], and resistance to cytotoxic chemotherapy in mCRC [12].

MSI was also considered important in guiding adjuvant therapy in stage II colon cancer in this survey. Specialists believed MSI was "likely" to influence decision making for adjuvant therapy in stage II colon cancer. MSI status may be useful in guiding adjuvant chemotherapy in stage II colon cancer [3]. MSI-H has been shown to have a protective effect in stage II/III colon cancer in a study by Sargent et al. and a more recent meta-analysis by Bockelman et al. [53,54]. As a result, stage II colon cancer patients with MSI-H tumours may be less likely to benefit from chemotherapy [54]. Furthermore, MSI has been shown to be important in the management of metastatic colon cancer as it selects patients who would benefit from immunotherapy as a second line agent $[11,12,55]$.

\subsubsection{Lymph Node Yield (LNY)}

A majority of colorectal cancer specialists identified lymph node yield (LNY) as a pathological feature of prognostic importance in this survey (81\%). LNY ranked 13 (of 17) in order of importance after IRT modelling. In the existing literature, LNY may be a strong prognostic factor, particularly for stage I-III colon cancer [56-61]. Improved prognosis independent of nodal stage has been observed in colon cancer with a higher LNY in terms of recurrence, DFS and mortality [57,58,60-63]. International guidelines recommend a LNY $\geq 12$ for adequate nodal staging $[3,4,11,12,24,64]$.

In stage II colon cancer, 54\% of clinicians believed LNY influences chemotherapy decision making, with an overall "neutral" view on IRT modelling. There is strong evidence that a low LNY increases the risk of recurrence [3,65]. LNY $<12$ is identified as a major prognostic factor in stage II disease for determining adjuvant chemotherapy in ESMO and NCCN guidelines $[3,10]$.

\subsubsection{BRAF Status}

In this study, 73\% of specialists identified BRAF as "likely" to or "definitely" influence prognosis. Within the literature, the prognosticative utility of BRAF remains controversial [66-70]. Of all BRAF mutations, the BRAF V600E mutation accounts for the majority (approximately 90\%) in colon cancer [71]. Current evidence leans towards poor prognostication in BRAF V600E-mt disease, though its prognosticative value may vary according to stage and MSI status [69,70,72-76]. In stage II and III colon cancer, studies have shown worse prognosis in BRAF V600E-mt patients, with increased mortality and reduced PFS [66,77]. In metastatic disease, BRAF V600E-mt confers resistance to EGFR inhibitor therapy [78-82]. The prognosticative ability of BRAF V600E may be augmented by the combination of other biomarker tests (PIK3CA, KRAS and NRAS) [83]. In the non-metastatic setting, testing for BRAF is recommended in patients with MSI-H colon cancer to identify those with Lynch syndrome; there is no current role in determining prognostication $[3,11,84]$. In metastatic colon cancer however, NICE (2020), ESMO (2014) and Australian (2017) guidelines highlight a role for BRAF testing for prognostication and prediction of resistance to anti-EGFR therapies [12,55,64]. 
Within our survey, BRAF was not seen as an important factor in guiding adjuvant therapy. BRAF ranked the 5 th most common pathological feature in which clinicians did not know if it affected prognosis or adjuvant therapy. The evidence for BRAF V600E as a biomarker in guiding recommendations for adjuvant chemotherapy in stage II colon cancer is scant. A 2011 study by Hutchins et al. looked 1913 patients from the QUASAR trial found no significant difference in recurrence risk between BRAF-mt and BRAF-wt patients, and did not identify BRAF as a useful biomarker to guide the use of chemotherapy [62].

\subsection{Grade IIb Features}

\subsubsection{Lymph Node Ratio (LNR)}

In this study, approximately two thirds of specialists believed that LNR "likely" or "definitely" influences prognosis. High LNR independently predicts reduced OS and DFS in stage III and metastatic disease [85-92]. Several systematic reviews and meta-analyses have demonstrated improved OS (2.36) and DFS (3.71) in colon cancer patients with lower LNR $[85,86]$. In addition, LNR has superior predictive capability compared to current Nstaging (number of positive nodes) in some studies [85,86,90]. The prognostic significance of LNR may be greater where LNY is $<12[88,93]$.

Current AJCC-UICC TNM staging does not consider LNR part of N-staging [4]. While several studies have demonstrated the prognosticative ability of LNR, it is not utilised in any international colon cancer guidelines $[3,10-13,55,64]$. Further research is required.

\subsubsection{Tumour Location}

In this study, tumour location ranked fourth last (of 23) in importance. However, recent literature has shown some potential utility in the prognostication of colon cancer. Right sided CRC have a greater tendency to metastasise to the peritoneal surface compared to left sided CRC which metastasises more frequently to liver and lung [94,95]. In the nonmetastatic setting, there may be some utility in prognostication, but the level of evidence is weak [96-101]. International guidelines do not consider tumour location as a major factor driving prognostication or management in non-metastatic CRC $[3,11,13,14]$.

In this study, tumour location ranks last in IRT analysis, with the consensus that tumour location should not be used to guide adjuvant therapy in stage II colon cancer. There is sparse evidence in the literature that tumour location may influence adjuvant therapy. Tumour sidedness is not factored in any international guideline in determining adjuvant therapy for stage II colon cancer $[5,6]$.

\subsection{Grade III Features \\ Tumour Size}

In this study, most specialists did not believe tumour size would influence prognosis. Tumour size was ranked second last in order of importance after IRT analysis. This is in line with the existing literature, which highlights an inconclusive role of tumour size in prognostication in colon cancer, despite its established utility in malignancies such as thyroid, breast and lung cancer [4]. Some studies have reported a worse prognosis with increasing tumour size in colon cancer [102-109]. Authors have postulated that inherent difficulties in achieving a complete $\mathrm{R} 0$ resection secondary due to its size or the vertical invasion mechanics of the tumour could potentially explain the survival difference [102]. Other studies have failed to find independent prognosticative ability of tumour size in colon cancer [9,110-116]. Significant heterogeneity within the literature is due to different tumour size cut-off values used in different studies, and defining a consensus cut-off is a direction for future research [117]. While histological reporting routinely record tumour size, it is not utilised in current TNM staging [4] or considered in routine management of colon malignancy $[3,10,14,55,64]$.

This study demonstrated that majority of specialists do not believe that tumour size influences decision making for adjuvant therapy in stage II colon cancer in our study. In the literature, tumour size is not included in any guidelines regarding colon cancer. 


\subsection{Other Features}

\subsubsection{Apical Lymph Nodes (ALN)}

In our study, a large proportion of specialists were aware of ALN and a majority of those believed it did influence prognostication in colon cancer. The impact of ALN involvement on prognostication is controversial [118-122]. Some authors have shown a positive ALN to independently predict poorer OS and DFS in colon cancer patients, with potentially better predictive capability than current $\mathrm{N}$ staging $[120,121,123,124]$. Other studies found that survival outcomes in patients with stage II disease and ALN involvement were similar to those with stage IV disease with R0 resection. As a result, some authors have argued that ALN metastasis reflected systematic involvement as opposed to regional spread $[121,125]$. On the other hand, several studies have not found such an association, suggesting that ALN involvement should be still seen as a regional metastasis rather than systemic metastases $[118,119,122,126]$. Currently there is no set consensus for the definition of ALN metastasis [127]. Current TNM nodal staging considers ALN as a regional lymph rather than a separate entity [4]. However, ALN nodal involvement is currently utilised in the current Australian and Japanese classification system for colon cancer [12,13]. ALN positivity (previously classified as N3) has been previously utilised in previous editions of the TNM staging system (3rd and 4th edition), but complexity in dividing lymph node zones for pathologic evaluation and inconsistent evidence in prognostication have led to its disuse in future editions [123].

ALN is not applicable in decision making for adjuvant therapy in stage II colon cancer as ALN positivity denotes at least stage III disease [4].

\subsubsection{Tumour Budding}

In this study, a significant proportion of specialists were unsure of the role of tumour budding in prognostication of colorectal cancer. This may be due to the fact that tumour budding is a less well-known pathological feature. In the literature, tumour budding has emerged as an independent prognostic biomarker in colon cancer [128]. Strong evidence has linked the presence of tumour budding with reduced OS and DFS in colon cancer [128-131]. Its utility is highest in early disease (stage I and II) due to its potential to identify patients at high risk of nodal dissemination $[128,132,133]$. In the last few years, tumour budding has been acknowledged as a potential tumour-related prognostic factor in latest AJCCUICC TNM classification system [4]. Latest UK, European and Japanese guidelines include tumour budding in the screening, diagnosis and treatment of colon cancer $[3,4,55,64,134]$ as a high-risk feature.

Forty-eight percent of specialists in this survey believed that tumour budding may influence decision making for adjuvant therapy in stage II colon cancer. On IRT modelling, tumour budding had an overall "neutral" ranking in influencing adjuvant therapy in stage II colon cancer. In the literature, the role for tumour budding to identify high risk stage II colon cancer patients who may benefit from adjuvant chemotherapy has been reported but not extensively studied $[129,130,135,136]$. Overall, tumour budding may represent a promising histological feature in influencing decision making for stage II colon cancer.

\subsubsection{Tumour Infiltrating Lymphocytes (TILs)}

The majority $(80 \%)$ of survey participants believed TILs to influence prognosis in colon cancer. This is consistent with the existing literature, where a high TIL count has shown to be associated with a better prognosis. Higher OS, CSS and DFS have been observed in colon cancer patients with higher density of TILs $[137,138]$. Subtypes of TILs shown to have greatest prognosticative ability include CD3, CD8 and FoxP3 cells $[138,139]$. Currently, assessment of TILs is not commonly used for prognostication in the clinical environment $[3,10-12,14,64]$. Recent updates to international guidelines have acknowledged the potential role of immunoclassification scores such as the Immunoscore (which include TIL assessment) alongside established TNM staging to guide prognostication and recurrence prediction in colon cancer $[3,140]$. 
Regarding guiding adjuvant therapy in stage II colon cancer, only a minority $(30 \%)$ of specialists believed that TILs would influence decision making. A small proportion of respondents $(5.93 \%)$ were unsure of the effect of TILs on adjuvant therapy. On IRT modelling, overall attitude towards TILs was "neutral", ranking TILs similar to BRAF status and tumour budding in guiding adjuvant chemotherapy. Current Australian colon cancer guidelines do not incorporate TILs into prognostication or adjuvant chemotherapy in stage II colon cancer management [12]. Some authors have highlighted the potential of TILs to guide decision making in adjuvant chemotherapy and immunotherapy $[138,139]$. ESMO guidelines discuss the role of scoring systems incorporating TIL counts (such as the Immunoscore) in determining recurrence risk in challenging cases of stage II colon cancer [3].

\subsubsection{KRAS Status}

In our study, KRAS did not rank high (18 of 23) in importance for guiding prognosis in colon cancer. This is in keeping with current literature, which has not definitively established KRAS mutation as an independent prognostic factor, especially in stage II and III colon cancer [141]. KRAS testing appears to be most useful in metastatic colon cancer and may be helpful in guiding responsiveness to anti-EGFR targeted therapy. In metastatic colon cancer, KRAS-mt has been associated with poorer prognosis, with lower OS and RFS compared to the KRAS-wt population [142-145]. A pooled analysis by Modest et al. of 1239 mCRC patients demonstrated that KRAS-mt patients had a reduced OS (HR 1.41, $p<0.001$ ) and PFS (HR 1.2, $p=0.03$ ) compared to the KRAS-wt cohort [82]. Evidence is less definitive in non-metastatic colon cancer. Multiple phase III chemotherapy trials have found an association between KRAS and poorer OS, DFS as well as an increased risk of recurrence [146-149]. However, other studies have reported KRAS to have no prognostic influence [146,150-152]. Currently KRAS mutation is considered an additional prognostic factor in AJCC-UICC staging [4].

In this study, only $31 \%$ of specialists believed KRAS would influence decision making for adjuvant chemotherapy in stage II disease. In the existing literature and established guidelines, routine testing of KRAS is not recommended in the workup of nonmetastatic colon cancer due to a lack of evidence in its utility for determination of adjuvant therapy $[3,12,64]$.

\subsubsection{CDX2 Status}

Our study found a significant uncertainty amongst specialists regarding CDX2 and its influence on prognosis and adjuvant therapy. A large percentage of specialists (42\%) were unsure if CDX2 affected prognosis. Traditionally used in identifying cancers of unknown origin [153], CDX2 has recently been identified as an emerging prognostic biomarker in colon cancer. Recent level 1 evidence highlights the association of a loss of CDX2 expression with worse prognostication in colon cancer (reduced OS and DFS) [154-156]. A recent systematic review and meta-analysis revealed that CDX2 expression reduced mortality, with a $50 \%$ reduction in death compared to patients with colorectal cancer with poor or no CDX2 expression. This association was more pronounced in stage II and III colon cancer, with up to $70 \%$ risk reduction in OS. CDX2 expression was also associated with up to a $52 \%$ lower risk of disease recurrence [155]. While some studies have demonstrated the association between CDX2 loss and negative prognosis, there are inconsistencies within the literature. Bruun et al. demonstrated that CDX2 was prognostic only in stage IV and stage III BRAF-mutated colon cancer patients [157]. Silk et al. showed that CDX2 loss was associated with worse prognosis only in the MSS cohort but not the MSI-H cohort in stage II colon cancer [158]. Other authors have failed to find an association between CDX2 and prognosis $[15,159,160]$. Currently CDX2 is not utilised in prognostication in colon cancer in the clinical setting. Current guidelines including NICE, NCCN, Australian and ESMO do not report CDX2 as a useful tool for prognostication $[3,10,12,55,64]$. 
A large proportion of specialists (32\%) were also unsure of the effect of CDX2 on adjuvant therapy. CDX2 ranked last in order of importance in affecting adjuvant therapy; the majority of specialists did not believe it had any value in prognosis or decision making for adjuvant chemotherapy. Currently, there is minimal literature on CDX2 influencing adjuvant therapy in stage II colon cancer and its role in prognostication has not yet been established [159].

\subsubsection{EGFR Status}

There was also uncertainty amongst specialists regarding EGFR and its influence on prognosis and adjuvant therapy. EGFR is commonly over expressed in colorectal cancer on immunohistochemical analysis; however, it has not been established as an independent prognostic variable [161]. Although rare in primary CRC [162], EGFR extracellular domain (ECD) mutations have been demonstrated in patients with mCRC treated with anti-EGFR therapy $[163,164]$. Patients with more prolonged responses to EGFR therapy preferentially develop EGFR ECD mutations compared to RAS mutations. These mutations are associated with the clonal evolution of drug-resistant cancer cells in patients treated with anti-EGFR antibodies. EGFR mutation testing is not routinely performed in primary CRC and its utility in $\mathrm{mCRC}$ is uncertain.

\subsection{Limitations of Study}

This study has some limitations. Firstly, because the PiCC UP study is a survey designed to assess the attitudes of specialist clinicians, this study does not provide the same level of evidence from clinical data seen in randomised control trials or cohort studies. Nonetheless, this survey to date was the largest survey of specialists in the Asia Pacific on the importance on different pathological features of colon cancer in guiding prognosis and adjuvant treatment. Another limitation was that due to the complex modelling required in IRT analysis, IRT scores was not computable for six pathological features in prognostication and eight pathological features for adjuvant therapy in stage II disease. However, IRT analysis is a commonly used form of analysis for survey-based studies that incorporates sophisticated mathematically modelling to analyse survey data. The IRT results in this study provided good correlation with both the weighted mean as well as Likert plot analysis reported in this study.

\section{Conclusions}

This study provides the most current perspectives by specialists on the importance of pathological features in prognostication and recommendations for adjuvant therapy in Australia and New Zealand. There is greater variation in specialist perspectives in recommendation for adjuvant therapy in stage II colon cancer than prognostication. In this study, the most important pathological features in prognostication were distant metastasis, lymph node metastases, tumour rupture, involved surgical margin, positive circumferential resection margin, lymphovascular invasion and histological grade. The pathological features that were considered important in guiding adjuvant therapy were tumour rupture, lymphovascular invasion and microsatellite instability. IHC markers such as CDX2, EGFR, KRAS and BRAF status present areas for further research to improve precision oncology. This is the largest survey of Australia and New Zealand specialists on pathological features in colon cancer and understanding the perspectives of key stakeholders in colon cancer management may be useful in informing future guidelines.

Author Contributions: The first draft of the manuscript was written by K.C. and H.W. The study conception, design performed by E.H. and J.W.T.T. Analysis of data was performed by I.Y.J.L. and J.W.T.T. Critical revisions were performed by K.C., G.C., H.W., I.Y.J.L. and J.W.T.T. All authors helped in revisions of the manuscript. All authors have read and agreed to the published version of the manuscript. The study uses data from the PiCC UP study Australia and New Zealand.

Funding: This research received no external funding. 
Institutional Review Board Statement: The study was conducted in accordance with the Declaration of Helsinki, and approved by Westmead Hospital (5270) AU RED LNR/17/WMEAD/343.

Informed Consent Statement: Completion of the PiCC UP survey was regarded as informed consent for participation.

Data Availability Statement: The data presented in this study are available on request from the corresponding author.

Acknowledgments: We would like to acknowledge and thank all participants who participated in the PiCC UP study.

Conflicts of Interest: The authors declare no conflict of interest.

Abbreviations

AJCC American Joint Committee on Cancer

ALN Apical Lymph Node

ASCO American Society of Clinical Oncology

ASCRS American Society of Colon and Rectal Surgeons

BRAF B-raf

CDX2 Caudal Type Homeobox 2

CI confidence interval

CRC colorectal cancer

CRM circumferential resection margin

CSS cancer specific survival

DFS disease free survival

EGFR epidermal growth factor receptor

ESMO European Society for Medical Oncology

HR hazard ratio

IHC immunohistochemistry

IRT item response theory

KRAS Kirsten rat sarcoma virus

LNR lymph node ratio

LNY lymph node yield

LVI lymphovascular invasion

mCRC metastatic colorectal cancer

MDT multidisciplinary team

MSI microsatellite instability

MSI-H MSI high

NCCN National Comprehensive Cancer Network

NCI National Cancer Institute

NHMRC National Health and Medical Research Council (Australia)

NICE National Institute for Health and Care Excellence

OS overall survival

PNI perineural invasion

RFS recurrence free survival

TILs tumour infiltrating lymphocytes

TNM Tumour, Node, Metastasis

UICC Union for international Cancer Control

\section{References}

1. O'Connell, J.B.; Maggard, M.A.; Ko, C.Y. Colon cancer survival rates with the new American Joint Committee on Cancer sixth edition staging. J. Natl. Cancer Inst. 2004, 96, 1420-1425. [CrossRef] [PubMed]

2. Schneider, N.I.; Langner, C. Prognostic stratification of colorectal cancer patients: Current perspectives. Cancer Manag. Res. 2014, 6, 291. [PubMed]

3. Argiles, G.; Tabernero, J.; Labianca, R.; Hochhauser, D.; Salazar, R.; Iveson, T.; Laurent-Puig, P.; Quirke, P.; Yoshino, T.; Taieb, J. Localised colon cancer: ESMO Clinical Practice Guidelines for diagnosis, treatment and follow-up. Ann. Oncol. 2020, 31 1291-1305. [CrossRef] [PubMed] 
4. Brierley, J.D.; Gospodarowicz, M.K.; Wittekind, C. TNM Classification of Malignant Tumours; John Wiley \& Sons: Hoboken, NJ USA, 2017.

5. Fang, S.H.; Efron, J.E.; Berho, M.E.; Wexner, S.D. Dilemma of stage II colon cancer and decision making for adjuvant chemotherapy J. Am. Coll. Surg. 2014, 219, 1056-1069. [CrossRef]

6. Zhang, C.; Yin, S.; Tan, Y.; Huang, J.; Wang, P.; Hou, W.; Zhang, Z.; Xu, H. Patient Selection for Adjuvant Chemotherapy in High-Risk Stage II Colon Cancer: A Systematic Review and Meta-Analysis. Am. J. Clin. Oncol. 2020, 43, 279-287. [CrossRef]

7. Kirkpatrick, H.M.; Aitelli, C.L.; Qin, H.; Becerra, C.; Lichliter, W.E.; McCollum, A.D. Referral patterns and adjuvant chemotherapy use in patients with stage II colon cancer. Clin. Colorectal Cancer 2010, 9, 150-156. [CrossRef]

8. Toh, J.W.T.; Mahajan, H.; Chapuis, P.; Spring, K. Current status on microsatellite instability, prognosis and adjuvant therapy in colon cancer: A nationwide survey of medical oncologists, colorectal surgeons and gastrointestinal pathologists. Cancer Rep. 2021, 4, e1297. [CrossRef]

9. Compton, C.C.; Fielding, L.P.; Burgart, L.J.; Conley, B.; Cooper, H.S.; Hamilton, S.R.; Hammond, M.E.H.; Henson, D.E.; Hutter, R.V.; Nagle, R.B. Prognostic factors in colorectal cancer: College of American Pathologists consensus statement 1999. Arch. Pathol. Lab. Med. 2000, 124, 979-994. [CrossRef]

10. Benson, A.B.; Venook, A.P.; Al-Hawary, M.M.; Arain, M.A.; Chen, Y.-J.; Ciombor, K.K.; Cohen, S.; Cooper, H.S.; Deming, D.; Farkas, L. Colon cancer, version 2.2021, NCCN clinical practice guidelines in oncology. J. Natl. Compr. Cancer Netw. 2021, 19, 329-359. [CrossRef]

11. Bromham, N.; Kallioinen, M.; Hoskin, P.; Davies, R.J. Colorectal cancer: Summary of NICE guidance. Br. Med. J. 2020, 368, 1-6. [CrossRef]

12. National Health and Medical Research Council. Clinical Practice Guidelines for the Prevention, Early Detection and Management of Colorectal Cancer. Available online: https://wiki.cancer.org.au/australia/Guidelines:Colorectal_cancer (accessed on 1 November 2021).

13. Hashiguchi, Y.; Muro, K.; Saito, Y.; Ito, Y.; Ajioka, Y.; Hamaguchi, T.; Hasegawa, K.; Hotta, K.; Ishida, H.; Ishiguro, M. Japanese Society for Cancer of the Colon and Rectum (JSCCR) guidelines 2019 for the treatment of colorectal cancer. Int. J. Clin. Oncol. 2020, 25, 1-42. [CrossRef] [PubMed]

14. Lopes, G.; Stern, M.C.; Temin, S.; Sharara, A.I.; Cervantes, A.; Costas-Chavarri, A.; Engineer, R.; Hamashima, C.; Ho, G.F.; Huitzil, F.D.; et al. Early Detection for Colorectal Cancer: ASCO Resource-Stratified Guideline. J. Glob. Oncol. 2019, 5, 1-22. [CrossRef] [PubMed]

15. Chen, K.; Collins, G.; Wang, H.; Toh, J.W.T. Pathological Features and Prognostication in Colorectal Cancer. Curr. Oncol. 2021, 28, 5356-5383. [CrossRef] [PubMed]

16. Zacharakis, M.; Xynos, I.D.; Lazaris, A.; Smaro, T.; Kosmas, C.; Dokou, A.; Felekouras, E.; Antoniou, E.; Polyzos, A.; Sarantonis, J. Predictors of survival in stage IV metastatic colorectal cancer. Anticancer Res. 2010, 30, 653-660.

17. Biller, L.H.; Schrag, D. Diagnosis and Treatment of Metastatic Colorectal Cancer: A Review. JAMA 2021, 325, 669-685. [CrossRef]

18. Ong, M.L.H.; Schofield, J.B. Assessment of lymph node involvement in colorectal cancer. World J. Gastrointest. Surg. 2016, 8, 179-192. [CrossRef]

19. Cohen, A.M.; Tremiterra, S.; Candela, F.; Thaler, H.T.; Sigurdson, E.R. Prognosis of node-positive colon cancer. Cancer 1991, 67, 1859-1861. [CrossRef]

20. Osterman, E.; Glimelius, B. Recurrence Risk After Up-to-Date Colon Cancer Staging, Surgery, and Pathology: Analysis of the Entire Swedish Population. Dis. Colon Rectum 2018, 61, 1016-1025. [CrossRef]

21. Sargent, D.; Sobrero, A.; Grothey, A.; O'Connell, M.J.; Buyse, M.; Andre, T.; Zheng, Y.; Green, E.; Labianca, R.; O'Callaghan, C.; et al. Evidence for cure by adjuvant therapy in colon cancer: Observations based on individual patient data from 20,898 patients on 18 randomized trials. J. Clin. Oncol. Off. J. Am. Soc. Clin. Oncol. 2009, 27, 872-877. [CrossRef]

22. Diaconescu, M.; Burada, F.; Mirea, C.S.; Moraru, E.; Ciorbagiu, M.C.; Obleaga, C.V.; Vilcea, I.D. T4 Colon Cancer-Current Management. Curr. Health Sci. J. 2018, 44, 5-13. [CrossRef]

23. Brown, P.K.I.; Rosty, C.; Ellis, D.; Ruszkiewicz, A.; Lokan, J.; McLeod, D.; Kramer, N.; Ackland, S.; Raftopoulos, S. Colorectal Cancer Structured Reporting Protocol, 4th ed.; Royal College of Pathologists of Australasia: Sydney, Australia, 2020.

24. College pof American Pathologists (CAP). Protocol for the Examination of Specimens from Patients with Primary Carcinoma of the Colon and Rectum; College of American Pathologists: Northfield, IL, USA, 2017.

25. Amri, R.; Bordeianou, L.G.; Sylla, P.; Berger, D.L. Association of Radial Margin Positivity with Colon Cancer. JAMA Surg. 2015, 150, 890-898. [CrossRef] [PubMed]

26. Tang, X.-Y.; Huang, M.-X.; Han, S.-Q.; Chang, Y.; Li, Z.-P.; Kao, X.-M.; Chen, Y.-Y.; Liu, C.; Huang, Y.-D.; Chen, Y.-T.; et al. The Circumferential Resection Margin Is a Prognostic Predictor in Colon Cancer. Front. Oncol. 2020, 10, 927. [CrossRef] [PubMed]

27. Al-Sukhni, E.; Attwood, K.; Gabriel, E.M.; LeVea, C.M.; Kanehira, K.; Nurkin, S.J. Lymphovascular and perineural invasion are associated with poor prognostic features and outcomes in colorectal cancer: A retrospective cohort study. Int. J. Surg. 2017, 37, 42-49. [CrossRef]

28. Gao, Z.; Cao, H.; Xu, X.; Wang, Q.; Wu, Y.; Lu, Q. Prognostic value of lymphovascular invasion in stage II colorectal cancer patients with an inadequate examination of lymph nodes. World J. Surg. Oncol. 2021, 19, 125. [CrossRef]

29. Lin, H.H.; Chang, Y.Y.; Lin, J.K.; Jiang, J.K.; Lin, C.C.; Lan, Y.T.; Yang, S.H.; Wang, H.S.; Chen, W.S.; Lin, T.C.; et al. The role of adjuvant chemotherapy in stage II colorectal cancer patients. Int. J. Colorectal Dis. 2014, 29, 1237-1243. [CrossRef] [PubMed] 
30. Skancke, M.; Arnott, S.M.; Amdur, R.L.; Siegel, R.S.; Obias, V.J.; Umapathi, B.A. Lymphovascular Invasion and Perineural Invasion Negatively Impact Overall Survival for Stage II Adenocarcinoma of the Colon. Dis. Colon Rectum 2019, 62, 181-188. [CrossRef]

31. Van Wyk, H.C.; Roxburgh, C.S.; Horgan, P.G.; Foulis, A.F.; McMillan, D.C. The detection and role of lymphatic and blood vessel invasion in predicting survival in patients with node negative operable primary colorectal cancer. Crit. Rev. Oncol. Hematol. 2014, 90, 77-90. [CrossRef]

32. Yuan, H.; Dong, Q.; Zheng, B.A.; Hu, X.; Xu, J.-B.; Tu, S. Lymphovascular invasion is a high risk factor for stage I/II colorectal cancer: A systematic review and meta-analysis. Oncotarget 2017, 8, 46565-46579. [CrossRef]

33. Zhong, J.-W.; Yang, S.-X.; Chen, R.-P.; Zhou, Y.-H.; Ye, M.-S.; Miao, L.; Xue, Z.-X.; Lu, G.-R. Prognostic Value of Lymphovascular Invasion in Patients with Stage III Colorectal Cancer: A Retrospective Study. Med. Sci. Monit. 2019, 25, 6043-6050. [CrossRef]

34. Booth, C.M.; Nanji, S.; Wei, X.; Peng, Y.; Biagi, J.J.; Hanna, T.P.; Krzyzanowska, M.K.; Mackillop, W.J. Adjuvant Chemotherapy for Stage II Colon Cancer: Practice Patterns and Effectiveness in the General Population. Clin. Oncol. 2017, 29, e29-e38. [CrossRef]

35. Fu, J.; Wu, L.; Ge, C.; Xu, T.; Li, D.; Fu, W.; Wang, L.; Du, J. De-escalating chemotherapy for stage II colon cancer? Ther. Adv. Gastroenterol. 2019, 12, 1756284819867553. [CrossRef] [PubMed]

36. Derwinger, K.; Kodeda, K.; Bexe-Lindskog, E.; Taflin, H. Tumour differentiation grade is associated with TNM staging and the risk of node metastasis in colorectal cancer. Acta Oncol. 2010, 49, 57-62. [CrossRef]

37. Barresi, V.; Reggiani Bonetti, L.; Ieni, A.; Caruso, R.A.; Tuccari, G. Histological grading in colorectal cancer: New insights and perspectives. Histol. Histopathol. 2015, 30, 1059-1067. [CrossRef] [PubMed]

38. Ueno, H.; Kajiwara, Y.; Shimazaki, H.; Shinto, E.; Hashiguchi, Y.; Nakanishi, K.; Maekawa, K.; Katsurada, Y.; Nakamura, T.; Mochizuki, H.; et al. New Criteria for Histologic Grading of Colorectal Cancer. Am. J. Surg. Pathol. 2012, 36, 193-201. [CrossRef] [PubMed]

39. Newland, R.C.; Dent, O.F.; Lyttle, M.N.; Chapuis, P.H.; Bokey, E.L. Pathologic determinants of survival associated with colorectal cancer with lymph node metastases. A multivariate analysis of 579 patients. Cancer 1994, 73, 2076-2082. [CrossRef]

40. Ueno, H.; Hase, K.; Hashiguchi, Y.; Shimazaki, H.; Tanaka, M.; Miyake, O.; Masaki, T.; Shimada, Y.; Kinugasa, Y.; Mori, Y.; et al. Site-specific tumor grading system in colorectal cancer: Multicenter pathologic review of the value of quantifying poorly differentiated clusters. Am. J. Surg. Pathol. 2014, 38, 197-204. [CrossRef]

41. Chapuis, P.H.; Dent, O.F.; Fisher, R.; Newland, R.C.; Pheils, M.T.; Smyth, E.; Colquhoun, K. A multivariate analysis of clinical and pathological variables in prognosis after resection of large bowel cancer. Br. J. Surg. 1985, 72, 698-702. [CrossRef]

42. Compton, C.; Fenoglio-Preiser, C.M.; Pettigrew, N.; Fielding, L.P. American Joint Committee on Cancer Prognostic Factors Consensus Conference: Colorectal Working Group. Cancer 2000, 88, 1739-1757. [CrossRef]

43. Knijn, N.; Mogk, S.C.; Teerenstra, S.; Simmer, F.; Nagtegaal, I.D. Perineural Invasion is a Strong Prognostic Factor in Colorectal Cancer: A Systematic Review. Am. J. Surg. Pathol. 2016, 40, 103-112. [CrossRef]

44. Ceyhan, G.O.; Liebl, F.; Maak, M.; Schuster, T.; Becker, K.; Langer, R.; Demir, I.E.; Hartel, M.; Friess, H.; Rosenberg, R. The severity of neural invasion is a crucial prognostic factor in rectal cancer independent of neoadjuvant radiochemotherapy. Ann. Surg. 2010 252, 797-804. [CrossRef]

45. Liebig, C.; Ayala, G.; Wilks, J.; Verstovsek, G.; Liu, H.; Agarwal, N.; Berger, D.H.; Albo, D. Perineural invasion is an independent predictor of outcome in colorectal cancer. J. Clin. Oncol. Off. J. Am. Soc. Clin. Oncol. 2009, 27, 5131-5137. [CrossRef] [PubMed]

46. Liebig, C.; Ayala, G.; Wilks, J.A.; Berger, D.H.; Albo, D. Perineural invasion in cancer: A review of the literature. Cancer: Interdiscip. Int. J. Am. Cancer Soc. 2009, 115, 3379-3391. [CrossRef]

47. Mayo, E.; Llanos, A.A.; Yi, X.; Duan, S.Z.; Zhang, L. Prognostic value of tumour deposit and perineural invasion status in colorectal cancer patients: A SEER-based population study. Histopathology 2016, 69, 230-238. [CrossRef] [PubMed]

48. Quah, H.-M.; Chou, J.F.; Gonen, M.; Shia, J.; Schrag, D.; Landmann, R.G.; Guillem, J.G.; Paty, P.B.; Temple, L.K.; Wong, W.D. Identification of patients with high-risk stage II colon cancer for adjuvant therapy. Dis. Colon Rectum 2008, 51, 503-507. [CrossRef] [PubMed]

49. Huh, J.W.; Kim, H.R.; Kim, Y.J. Prognostic value of perineural invasion in patients with stage II colorectal cancer. Ann. Surg. Oncol. 2010, 17, 2066-2072. [CrossRef] [PubMed]

50. Popat, S.; Hubner, R.; Houlston, R.S. Systematic review of microsatellite instability and colorectal cancer prognosis. J. Clin. Oncol. Off. J. Am. Soc. Clin. Oncol. 2005, 23, 609-618. [CrossRef]

51. Guastadisegni, C.; Colafranceschi, M.; Ottini, L.; Dogliotti, E. Microsatellite instability as a marker of prognosis and response to therapy: A meta-analysis of colorectal cancer survival data. Eur. J. Cancer 2010, 46, 2788-2798. [CrossRef]

52. Gelsomino, F.; Barbolini, M.; Spallanzani, A.; Pugliese, G.; Cascinu, S. The evolving role of microsatellite instability in colorectal cancer: A review. Cancer Treat. Rev. 2016, 51, 19-26. [CrossRef]

53. Böckelman, C.; Engelmann, B.E.; Kaprio, T.; Hansen, T.F.; Glimelius, B. Risk of recurrence in patients with colon cancer stage II and III: A systematic review and meta-analysis of recent literature. Acta Oncol. 2015, 54, 5-16. [CrossRef]

54. Sargent, D.J.; Marsoni, S.; Monges, G.; Thibodeau, S.N.; Labianca, R.; Hamilton, S.R.; French, A.J.; Kabat, B.; Foster, N.R.; Torri, V. Defective mismatch repair as a predictive marker for lack of efficacy of fluorouracil-based adjuvant therapy in colon cancer. $J$. Clin. Oncol. 2010, 28, 3219. [CrossRef] 
55. Van Cutsem, E.; Cervantes, A.; Adam, R.; Sobrero, A.; Van Krieken, J.H.; Aderka, D.; Aranda Aguilar, E.; Bardelli, A.; Benson, A.; Bodoky, G.; et al. ESMO consensus guidelines for the management of patients with metastatic colorectal cancer. Ann. Oncol. Off. J. Eur. Soc. Med. Oncol. 2016, 27, 1386-1422. [CrossRef] [PubMed]

56. Backes, Y.; Elias, S.G.; Bhoelan, B.S.; Groen, J.N.; van Bergeijk, J.; Seerden, T.C.J.; Pullens, H.J.M.; Spanier, B.W.M.; Geesing, J.M.J.; Kessels, K.; et al. The prognostic value of lymph node yield in the earliest stage of colorectal cancer: A multicenter cohort study. BMC Med. 2017, 15, 129. [CrossRef] [PubMed]

57. Betge, J.; Harbaum, L.; Pollheimer, M.J.; Lindtner, R.A.; Kornprat, P.; Ebert, M.P.; Langner, C. Lymph node retrieval in colorectal cancer: Determining factors and prognostic significance. Int. J. Colorectal Dis. 2017, 32, 991-998. [CrossRef] [PubMed]

58. Chang, G.J.; Rodriguez-Bigas, M.A.; Skibber, J.M.; Moyer, V.A. Lymph node evaluation and survival after curative resection of colon cancer: Systematic review. J. Natl. Cancer Inst. 2007, 99, 433-441. [CrossRef]

59. Foo, C.C.; Ku, C.; Wei, R.; Yip, J.; Tsang, J.; Chan, T.Y.; Lo, O.; Law, W.L. How does lymph node yield affect survival outcomes of stage I and II colon cancer? World J. Surg. Oncol. 2020, 18, 22. [CrossRef]

60. Le Voyer, T.E.; Sigurdson, E.R.; Hanlon, A.L.; Mayer, R.J.; Macdonald, J.S.; Catalano, P.J.; Haller, D.G. Colon Cancer Survival Is Associated with Increasing Number of Lymph Nodes Analyzed: A Secondary Survey of Intergroup Trial INT-0089. J. Clin. Oncol. 2003, 21, 2912-2919. [CrossRef]

61. Lee, C.H.A.; Wilkins, S.; Oliva, K.; Staples, M.P.; McMurrick, P.J. Role of lymph node yield and lymph node ratio in predicting outcomes in non-metastatic colorectal cancer. BJS Open 2018, 3, 95-105. [CrossRef]

62. Roth, A.D.; Delorenzi, M.; Tejpar, S.; Yan, P.; Klingbiel, D.; Fiocca, R.; d'Ario, G.; Cisar, L.; Labianca, R.; Cunningham, D.; et al. Integrated Analysis of Molecular and Clinical Prognostic Factors in Stage II/III Colon Cancer. JNCI: J. Natl. Cancer Inst. 2012, 104, 1635-1646. [CrossRef]

63. Sarli, L.; Bader, G.; Iusco, D.; Salvemini, C.; Di Mauro, D.; Mazzeo, A.; Regina, G.; Roncoroni, L. Number of lymph nodes examined and prognosis of TNM stage II colorectal cancer. Eur. J. Cancer 2005, 41, 272-279. [CrossRef]

64. Baum, M.; Fallowfield, L.; Farewell, V.; Macbeth, F.; Treasure, T. NICE Guidelines: Management of colorectal cancer metastases. Br. J. Surg. 2020, 107, e357. [CrossRef]

65. Roth, A.D.; Tejpar, S.; Delorenzi, M.; Yan, P.; Fiocca, R.; Klingbiel, D.; Dietrich, D.; Biesmans, B.; Bodoky, G.; Barone, C.; et al. Prognostic role of KRAS and BRAF in stage II and III resected colon cancer: Results of the translational study on the PETACC-3, EORTC 40993, SAKK 60-00 trial. J. Clin. Oncol. Off. J. Am. Soc. Clin. Oncol. 2010, 28, 466-474. [CrossRef] [PubMed]

66. Phipps, A.I.; Alwers, E.; Harrison, T.; Banbury, B.; Brenner, H.; Campbell, P.T.; Chang-Claude, J.; Buchanan, D.; Chan, A.T.; Farris, A.B.; et al. Association Between Molecular Subtypes of Colorectal Tumors and Patient Survival, Based on Pooled Analysis of 7 International Studies. Gastroenterology 2020, 158, 2158-2168. [CrossRef] [PubMed]

67. Nazemalhosseini-Mojarad, E.; Kishani Farahani, R.; Mehrizi, M.; Baghaei, K.; Yaghoob Taleghani, M.; Golmohammadi, M.; Peyravian, N.; Ashtari, S.; Pourhoseingholi, M.A.; Asadzadeh Aghdaei, H.; et al. Prognostic Value of BRAF and KRAS Mutation in Relation to Colorectal Cancer Survival in Iranian Patients: Correlated to Microsatellite Instability. J. Gastrointest. Cancer 2020, 51, 53-62. [CrossRef]

68. Liou, J.M.; Wu, M.S.; Shun, C.T.; Chiu, H.M.; Chen, M.J.; Chen, C.C.; Wang, H.P.; Lin, J.T.; Liang, J.T. Mutations in BRAF correlate with poor survival of colorectal cancers in Chinese population. Int. J. Colorectal Dis. 2011, 26, 1387-1395. [CrossRef] [PubMed]

69. Chen, D.; Huang, J.F.; Liu, K.; Zhang, L.Q.; Yang, Z.; Chuai, Z.R.; Wang, Y.X.; Shi, D.C.; Huang, Q.; Fu, W.L. BRAFV600E mutation and its association with clinicopathological features of colorectal cancer: A systematic review and meta-analysis. PLoS ONE 2014, 9, e90607. [CrossRef]

70. Sclafani, F.; Gullo, G.; Sheahan, K.; Crown, J. BRAF mutations in melanoma and colorectal cancer: A single oncogenic mutation with different tumour phenotypes and clinical implications. Crit. Rev. Oncol. Hematol. 2013, 87, 55-68. [CrossRef]

71. Clarke, C.N.; Kopetz, E.S. BRAF mutant colorectal cancer as a distinct subset of colorectal cancer: Clinical characteristics, clinical behavior, and response to targeted therapies. J. Gastrointest. Oncol. 2015, 6, 660-667. [CrossRef]

72. French, A.J.; Sargent, D.J.; Burgart, L.J.; Foster, N.R.; Kabat, B.F.; Goldberg, R.; Shepherd, L.; Windschitl, H.E.; Thibodeau, S.N. Prognostic significance of defective mismatch repair and BRAF V600E in patients with colon cancer. Clin. Cancer Res. Off. J. Am. Assoc. Cancer Res. 2008, 14, 3408-3415. [CrossRef]

73. Samowitz, W.S.; Sweeney, C.; Herrick, J.; Albertsen, H.; Levin, T.R.; Murtaugh, M.A.; Wolff, R.K.; Slattery, M.L. Poor survival associated with the BRAF V600E mutation in microsatellite-stable colon cancers. Cancer Res. 2005, 65, 6063-6069. [CrossRef]

74. Ogino, S.; Nosho, K.; Kirkner, G.J.; Kawasaki, T.; Meyerhardt, J.A.; Loda, M.; Giovannucci, E.L.; Fuchs, C.S. CpG island methylator phenotype, microsatellite instability, BRAF mutation and clinical outcome in colon cancer. Gut 2009, 58, 90-96. [CrossRef]

75. Taieb, J.; Le Malicot, K.; Shi, Q.; Penault-Llorca, F.; Bouché, O.; Tabernero, J.; Mini, E.; Goldberg, R.M.; Folprecht, G.; Luc Van Laethem, J.; et al. Prognostic Value of BRAF and KRAS Mutations in MSI and MSS Stage III Colon Cancer. J. Natl. Cancer Inst. 2017, 109, djw272. [CrossRef] [PubMed]

76. De Cuba, E.M.; Snaebjornsson, P.; Heideman, D.A.; van Grieken, N.C.; Bosch, L.J.; Fijneman, R.J.; Belt, E.; Bril, H.; Stockmann, H.B.; Hooijberg, E.; et al. Prognostic value of BRAF and KRAS mutation status in stage II and III microsatellite instable colon cancers. Int. J. Cancer 2016, 138, 1139-1145. [CrossRef] [PubMed]

77. Rowland, A.; Dias, M.M.; Wiese, M.D.; Kichenadasse, G.; McKinnon, R.A.; Karapetis, C.S.; Sorich, M.J. Meta-analysis of BRAF mutation as a predictive biomarker of benefit from anti-EGFR monoclonal antibody therapy for RAS wild-type metastatic colorectal cancer. Br. J. Cancer 2015, 112, 1888-1894. [CrossRef] [PubMed] 
78. Tran, B.; Kopetz, S.; Tie, J.; Gibbs, P.; Jiang, Z.Q.; Lieu, C.H.; Agarwal, A.; Maru, D.M.; Sieber, O.; Desai, J. Impact of BRAF mutation and microsatellite instability on the pattern of metastatic spread and prognosis in metastatic colorectal cancer. Cancer 2011, 117, 4623-4632. [CrossRef] [PubMed]

79. Venderbosch, S.; Nagtegaal, I.D.; Maughan, T.S.; Smith, C.G.; Cheadle, J.P.; Fisher, D.; Kaplan, R.; Quirke, P.; Seymour, M.T.; Richman, S.D.; et al. Mismatch repair status and BRAF mutation status in metastatic colorectal cancer patients: A pooled analysis of the CAIRO, CAIRO2, COIN, and FOCUS studies. Clin. Cancer Res. Off. J. Am. Assoc. Cancer Res. 2014, 20, 5322-5330. [CrossRef] [PubMed]

80. Sanz-Garcia, E.; Argiles, G.; Elez, E.; Tabernero, J. BRAF mutant colorectal cancer: Prognosis, treatment, and new perspectives. Ann. Oncol. Off. J. Eur. Soc. Med. Oncol. 2017, 28, 2648-2657. [CrossRef] [PubMed]

81. Bokemeyer, C.; Kohne, C.; Rougier, P.; Stroh, C.; Schlichting, M.; Van Cutsem, E. Cetuximab with chemotherapy (CT) as first-line treatment for metastatic colorectal cancer $(\mathrm{mCRC})$ : Analysis of the CRYSTAL and OPUS studies according to KRAS and BRAF mutation status. J. Clin. Oncol. 2010, 28, 3506. [CrossRef]

82. Modest, D.P.; Ricard, I.; Heinemann, V.; Hegewisch-Becker, S.; Schmiegel, W.; Porschen, R.; Stintzing, S.; Graeven, U.; Arnold, D.; von Weikersthal, L.F.; et al. Outcome according to KRAS-, NRAS- and BRAF-mutation as well as KRAS mutation variants: Pooled analysis of five randomized trials in metastatic colorectal cancer by the AIO colorectal cancer study group. Ann. Oncol. 2016, 27, 1746-1753. [CrossRef]

83. Li, L.; Ni, B.B.; Zhong, Q.H.; Liu, Y.H.; Zhang, M.H.; Zhang, K.P.; Chen, D.C.; Wang, L. Investigation of correlation between mutational status in key EGFR signaling genes and prognosis of stage II colorectal cancer. Future Oncol. 2017, 13, 1473-1492. [CrossRef]

84. Chan, C.; Pierre Chapuis, D.S. Notable Differences Between Available Clinicopathological Staging Systems. Available online: https:/ / wiki.cancer.org.au/australiawiki/index.php?oldid=173067 (accessed on 3 September 2021).

85. Ceelen, W.; Van Nieuwenhove, Y.; Pattyn, P. Prognostic value of the lymph node ratio in stage III colorectal cancer: A systematic review. Ann. Surg. Oncol. 2010, 17, 2847-2855. [CrossRef]

86. Pyo, J.S.; Kim, J.H.; Lee, S.Y.; Baek, T.H.; Kang, D.W. Metastatic Lymph Node Ratio (mLNR) is a Useful Parameter in the Prognosis of Colorectal Cancer; A Meta-Analysis for the Prognostic Role of mLNR. Medicina 2019, 55, 673. [CrossRef] [PubMed]

87. Ozawa, T.; Ishihara, S.; Nishikawa, T.; Tanaka, T.; Tanaka, J.; Kiyomatsu, T.; Hata, K.; Kawai, K.; Nozawa, H.; Kanazawa, T.; et al. Prognostic significance of the lymph node ratio in stage IV colorectal cancer patients who have undergone curative resection. Ann. Surg. Oncol. 2015, 22, 1513-1519. [CrossRef] [PubMed]

88. Jiang, K.; Zhu, Y.; Liu, Y.; Ye, Y.; Xie, Q.; Yang, X.; Wang, S. Lymph node ratio as an independent prognostic indicator in stage III colorectal cancer: Especially for fewer than 12 lymph nodes examined. Tumour Biol. J. Int. Soc. Oncodev. Biol. Med. 2014, 35, 11685-11690. [CrossRef] [PubMed]

89. Jiang, C.; Wang, F.; Guo, G.; Dong, J.; Liu, S.; He, W.; Zhang, B.; Xia, L. Metastatic lymph node ratio as a prognostic indicator in patients with stage IV colon cancer undergoing resection. J. Cancer 2019, 10, 2534-2540. [CrossRef]

90. Deng, Y.; Peng, J.; Zhao, Y.; Sui, Q.; Zhao, R.; Lu, Z.; Qiu, M.; Lin, J.; Pan, Z. Lymph node ratio as a valuable prognostic factor for patients with colorectal liver-only metastasis undergoing curative resection. Cancer Manag. Res. 2018, 10, 2083-2094. [CrossRef]

91. Ahmed, S.; Leis, A.; Chandra-Kanthan, S.; Fields, A.; Zaidi, A.; Abbas, T.; Le, D.; Reeder, B.; Pahwa, P. Regional Lymph Nodes Status and Ratio of Metastatic to Examined Lymph Nodes Correlate with Survival in Stage IV Colorectal Cancer. Ann. Surg. Oncol. 2016, 23, 2287-2294. [CrossRef]

92. Rosenberg, R.; Engel, J.; Bruns, C.; Heitland, W.; Hermes, N.; Jauch, K.-W.; Kopp, R.; Pütterich, E.; Ruppert, R.; Schuster, T.; et al. The Prognostic Value of Lymph Node Ratio in a Population-Based Collective of Colorectal Cancer Patients. Ann. Surg. 2010, 251, 1070-1078. [CrossRef]

93. Peschaud, F.; Benoist, S.; Julié, C.; Beauchet, A.; Penna, C.; Rougier, P.; Nordlinger, B. The ratio of metastatic to examined lymph nodes is a powerful independent prognostic factor in rectal cancer. Ann. Surg. 2008, 248, 1067-1073. [CrossRef]

94. Kishiki, T.; Kuchta, K.; Matsuoka, H.; Kojima, K.; Asou, N.; Beniya, A.; Yamauchi, S.; Sugihara, K.; Masaki, T. The impact of tumor location on the biological and oncological differences of colon cancer: Multi-institutional propensity score-matched study. Am. J. Surg. 2019, 217, 46-52. [CrossRef]

95. Kerscher, A.G.; Chua, T.C.; Gasser, M.; Maeder, U.; Kunzmann, V.; Isbert, C.; Germer, C.T.; Pelz, J.O.W. Impact of peritoneal carcinomatosis in the disease history of colorectal cancer management: A longitudinal experience of 2406 patients over two decades. Br. J. Cancer 2013, 108, 1432-1439. [CrossRef]

96. Schrag, D.; Weng, S.; Brooks, G.; Meyerhardt, J.A.; Venook, A.P. The relationship between primary tumor sidedness and prognosis in colorectal cancer. Am. Soc. Clin. Oncol. 2016, 34, 3505. [CrossRef]

97. Li, Y.; Feng, Y.; Dai, W.; Li, Q.; Cai, S.; Peng, J. Prognostic effect of tumor sidedness in colorectal cancer: A SEER-based analysis. Clin. Colorectal Cancer 2019, 18, e104-e116. [CrossRef] [PubMed]

98. Loupakis, F.; Yang, D.; Yau, L.; Feng, S.; Cremolini, C.; Zhang, W.; Maus, M.K.; Antoniotti, C.; Langer, C.; Scherer, S.J.; et al. Primary tumor location as a prognostic factor in metastatic colorectal cancer. J. Natl. Cancer Inst. 2015, 107, 1. [CrossRef] [PubMed]

99. Stintzing, S.; Tejpar, S.; Gibbs, P.; Thiebach, L.; Lenz, H.-J. Understanding the role of primary tumour localisation in colorectal cancer treatment and outcomes. Eur. J. Cancer 2017, 84, 69-80. [CrossRef]

100. Zheng, C.; Jiang, F.; Lin, H.; Li, S. Clinical characteristics and prognosis of different primary tumor location in colorectal cancer: A population-based cohort study. Clin. Transl. Oncol. 2019, 21, 1524-1531. [CrossRef] 
101. Xie, M.-Z.; Li, J.-L.; Cai, Z.-M.; Li, K.-Z.; Hu, B.-L. Impact of primary colorectal Cancer location on the KRAS status and its prognostic value. BMC Gastroenterol. 2019, 19, 46. [CrossRef]

102. Feng, H.; Lyu, Z.; Zheng, J.; Zheng, C.; Wu, D.q.; Liang, W.; Li, Y. Association of tumor size with prognosis in colon cancer: A Surveillance, Epidemiology, and End Results (SEER) database analysis. Surgery 2021, 169, 1116-1123. [CrossRef]

103. Yan, Q.; Zhang, K.; Guo, K.; Liu, S.; Wasan, H.S.; Jin, H.; Yuan, L.; Feng, G.; Shen, F.; Shen, M. Value of tumor size as a prognostic factor in metastatic colorectal cancer patients after chemotherapy: A population-based study. Future Oncol. 2019, 15, 1745-1758. [CrossRef]

104. Dai, W.; Li, Y.; Meng, X.; Cai, S.; Li, Q.; Cai, G. Does tumor size have its prognostic role in colorectal cancer? Re-evaluating its value in colorectal adenocarcinoma with different macroscopic growth pattern. Int. J. Surg. 2017, 45, 105-112. [CrossRef]

105. Tayyab, M.; Razack, A.; Sharma, A.; Gunn, J.; Hartley, J.E. Correlation of rectal tumor volumes with oncological outcomes for low rectal cancers: Does tumor size matter? Surg. Today 2015, 45, 826-833. [CrossRef]

106. Kornprat, P.; Pollheimer, M.J.; Lindtner, R.A.; Schlemmer, A.; Rehak, P.; Langner, C. Value of tumor size as a prognostic variable in colorectal cancer: A critical reappraisal. Am. J. Clin. Oncol. 2011, 34, 43-49. [CrossRef] [PubMed]

107. Saha, S.; Shaik, M.; Johnston, G.; Saha, S.K.; Berbiglia, L.; Hicks, M.; Gernand, J.; Grewal, S.; Arora, M.; Wiese, D. Tumor size predicts long-term survival in colon cancer: An analysis of the National Cancer Data Base. Am. J. Surg. 2015, 209, 570-574. [CrossRef] [PubMed]

108. Liang, Y.; Li, Q.; He, D.; Chen, Y.; Li, J. Tumor size improves the accuracy of the prognostic prediction of T4a stage colon cancer. Sci. Rep. 2021, 11, 16264. [CrossRef] [PubMed]

109. Mejri, N.; Dridi, M.; El Benna, H.; Labidi, S.; Daoud, N.; Boussen, H. Prognostic value of tumor size in stage II and III colorectal cancer in Tunisian population. Colorectal Cancer 2017, 6, 113-119. [CrossRef]

110. Miller, W.; Ota, D.; Giacco, G.; Guinee, V.; Irimura, T.; Nicolson, G.; Cleary, K. Absence of a relationship of size of primary colon carcinoma with metastasis and survival. Clin. Exp. Metastasis 1985, 3, 189-196. [CrossRef] [PubMed]

111. Kanemitsu, Y.; Kato, T.; Hirai, T.; Yasui, K.; Morimoto, T.; Shimizu, Y.; Kodera, Y.; Yamamura, Y. Survival after curative resection for mucinous adenocarcinoma of the colorectum. Dis. Colon Rectum 2003, 46, 160-167. [CrossRef]

112. Griffin, M.R.; Bergstralh, E.J.; Coffey, R.J.; Beart Jr, R.W.; Melton III, L.J. Predictors of survival after curative resection of carcinoma of the colon and rectum. Cancer 1987, 60, 2318-2324. [CrossRef]

113. D'Eredita, G.; Serio, G.; Neri, V.; Polizzi, R.A.; Barberio, G.; Losacco, T. A survival regression analysis of prognostic factors in colorectal cancer. Aust. N. Z. J. Surg. 1996, 66, 445-451. [CrossRef]

114. Park, Y.J.; Park, K.J.; Park, J.-G.; Lee, K.U.; Choe, K.J.; Kim, J.-P. Prognostic factors in 2230 Korean colorectal cancer patients: Analysis of consecutively operated cases. World J. Surg. 1999, 23, 721-726. [CrossRef]

115. Crozier, J.E.; McMillan, D.C.; McArdle, C.S.; Angerson, W.J.; Anderson, J.H.; Horgan, P.G.; McKee, R.F. Tumor size is associated with the systemic inflammatory response but not survival in patients with primary operable colorectal cancer. J. Gastroenterol. Hepatol. 2007, 22, 2288-2291. [CrossRef]

116. Wang, W.-S.; Lin, J.-K.; Chiou, T.-J.; Liu, J.-H.; Fan, F.S.; Yen, C.-C.; Lin, T.-C.; Jiang, J.-K.; Yang, S.-H.; Wang, H.-S. Preoperative carcinoembryonic antigen level as an independent prognostic factor in colorectal cancer: Taiwan experience. Jpn. J. Clin. Oncol. 2000, 30, 12-16. [CrossRef] [PubMed]

117. Poritz, L.S.; Sehgal, R.; Hartnett, K.; Berg, A.; Koltun, W.A. Tumor volume and percent positive lymph nodes as a predictor of 5-year survival in colorectal cancer. Surgery 2011, 150, 649-655. [CrossRef] [PubMed]

118. Wang, L.; Hirano, Y.; Ishii, T.; Kondo, H.; Hara, K.; Obara, N.; Asari, M.; Yamaguchi, S. The role of apical lymph node metastasis in right colon cancer. Int. J. Colorectal Dis. 2020, 35, 1887-1894. [CrossRef] [PubMed]

119. Wang, L.; Hirano, Y.; Heng, G.; Ishii, T.; Kondo, H.; Hara, K.; Obara, N.; Asari, M.; Yamaguchi, S. Prognostic Utility of Apical Lymph Node Metastasis in Patients with Left-sided Colorectal Cancer. In Vivo 2020, 34, 2981-2989. [CrossRef]

120. Kang, J.; Hur, H.; Min, B.S.; Kim, N.K.; Lee, K.Y. Prognostic Impact of Inferior Mesenteric Artery Lymph Node Metastasis in Colorectal Cancer. Ann. Surg. Oncol. 2011, 18, 704-710. [CrossRef]

121. Kim, J.C.; Lee, K.H.; Yu, C.S.; Kim, H.C.; Kim, J.R.; Chang, H.M.; Kim, J.H.; Kim, J.S.; Kim, T.W. The clinicopathological significance of inferior mesenteric lymph node metastasis in colorectal cancer. Eur. J. Surg. Oncol. J. Eur. Soc. Surg. Oncol. Br. Assoc. Surg. Oncol. 2004, 30, 271-279. [CrossRef]

122. Yi, J.-W.; Lee, T.-G.; Lee, H.-S.; Heo, S.C.; Jeong, S.-Y.; Park, K.J.; Kang, S.-B. Apical-node metastasis in sigmoid colon or rectal cancer: Is it a factor that indicates a poor prognosis after high ligation? Int. J. Colorectal Dis. 2012, 27, 81-87. [CrossRef]

123. Tsai, H.-L.; Chen, Y.-T.; Yeh, Y.-S.; Huang, C.-W.; Ma, C.-J.; Wang, J.-Y. Apical Lymph Nodes in the Distant Metastases and Prognosis of Patients with Stage III Colorectal Cancer with Adequate Lymph Node Retrieval Following FOLFOX Adjuvant Chemotherapy. Pathol. Oncol. Res. 2018, 25, 905-913. [CrossRef]

124. Chafai, N.; Chan, C.L.; Bokey, E.L.; Dent, O.F.; Sinclair, G.; Chapuis, P.H. What factors influence survival in patients with unresected synchronous liver metastases after resection of colorectal cancer? Colorectal Dis. Off. J. Assoc. Coloproctology Great Br. Irel. 2005, 7, 176-181. [CrossRef]

125. Huh, J.W.; Kim, Y.J.; Kim, H.R. Distribution of lymph node metastases is an independent predictor of survival for sigmoid colon and rectal cancer. Ann. Surg. 2012, 255, 70-78. [CrossRef] 
126. Si, M.-B.; Yan, P.-J.; Du, Z.-Y.; Li, L.-Y.; Tian, H.-W.; Jiang, W.-J.; Jing, W.-T.; Yang, J.; Han, C.-W.; Shi, X.-E.; et al. Lymph node yield, survival benefit, and safety of high and low ligation of the inferior mesenteric artery in colorectal cancer surgery: A systematic review and meta-analysis. Int. J. Colorectal Dis. 2019, 34, 947-962. [CrossRef] [PubMed]

127. Gundara, J.; Gill, A.; Hugh, T.; Samra, J. Redefining the apical lymph node at right hemicolectomy. Eur. J. Surg. Oncol. (EJSO) 2013, 39, 662-665. [CrossRef] [PubMed]

128. Mitrovic, B.; Handley, K.; Assarzadegan, N.; Li Chang, H.H.; Dawson, H.; Grin, A.; Hutchins, G.; Magill, L.; Quirke, P.; Riddell, R.; et al. Prognostic and predictive value of tumour budding in stage II colorectal carcinoma. J. Clin. Oncol. 2015, 33, 3605. [CrossRef]

129. Lugli, A.; Zlobec, I.; Berger, M.D.; Kirsch, R.; Nagtegaal, I.D. Tumour budding in solid cancers. Nat. Rev. Clin. Oncol. 2021, 18, 101-115. [CrossRef] [PubMed]

130. Koelzer, V.H.; Zlobec, I.; Lugli, A. Tumor budding in colorectal cancer-Ready for diagnostic practice? Hum. Pathol. 2016, 47, 4-19. [CrossRef]

131. Sy, J.; Fung, C.L.; Dent, O.F.; Chapuis, P.H.; Bokey, L.; Chan, C. Tumor budding and survival after potentially curative resection of node-positive colon cancer. Dis. Colon Rectum 2010, 53, 301-307. [CrossRef]

132. Canguçu, A.L.; Valério, E.; Peixoto, R.B.P.; Felismino, T.C.; de Mello, C.A.L.; Neotti, T.; Calsavara, V.F.; de Macedo, M.P.; Júnior, S.A.; Riechelmann, R. The prognostic influence of tumour budding in Western patients with stage II colorectal cancer. Ecancermedicalscience 2020, 14, 1130.

133. Ueno, H.; Ishiguro, M.; Nakatani, E.; Ishikawa, T.; Uetake, H.; Matsuda, C.; Nakamoto, Y.; Kotake, M.; Kurachi, K.; Egawa, T.; et al. Prospective Multicenter Study on the Prognostic and Predictive Impact of Tumor Budding in Stage II Colon Cancer: Results from the SACURA Trial. J. Clin. Oncol. 2019, 37, 1886-1894. [CrossRef]

134. Watanabe, T.; Muro, K.; Ajioka, Y.; Hashiguchi, Y.; Ito, Y.; Saito, Y.; Hamaguchi, T.; Ishida, H.; Ishiguro, M.; Ishihara, S. Japanese Society for Cancer of the Colon and Rectum (JSCCR) guidelines 2016 for the treatment of colorectal cancer. Int. J. Clin. Oncol. 2018, 23, 1-34. [CrossRef]

135. Dawson, H.; Galuppini, F.; Träger, P.; Berger, M.D.; Studer, P.; Brügger, L.; Zlobec, I.; Inderbitzin, D.; Lugli, A. Validation of the International Tumor Budding Consensus Conference 2016 recommendations on tumor budding in stage I-IV colorectal cancer. Hum. Pathol. 2019, 85, 145-151. [CrossRef]

136. Van Wyk, H.C.; Park, J.; Roxburgh, C.; Horgan, P.; Foulis, A.; McMillan, D.C. The role of tumour budding in predicting survival in patients with primary operable colorectal cancer: A systematic review. Cancer Treat. Rev. 2015, 41, 151-159. [CrossRef] [PubMed]

137. Zhao, Y.; Ge, X.; He, J.; Cheng, Y.; Wang, Z.; Wang, J.; Sun, L. The prognostic value of tumor-infiltrating lymphocytes in colorectal cancer differs by anatomical subsite: A systematic review and meta-analysis. World J. Surg. Oncol. 2019, 17, 85. [CrossRef]

138. Idos, G.E.; Kwok, J.; Bonthala, N.; Kysh, L.; Gruber, S.B.; Qu, C. The Prognostic Implications of Tumor Infiltrating Lymphocytes in Colorectal Cancer: A Systematic Review and Meta-Analysis. Sci. Rep. 2020, 10, 3360. [CrossRef] [PubMed]

139. Malka, D.; Lièvre, A.; André, T.; Taïeb, J.; Ducreux, M.; Bibeau, F. Immune scores in colorectal cancer: Where are we? Eur. J. Cancer 2020, 140, 105-118. [CrossRef] [PubMed]

140. Nagtegaal, I.D.; Odze, R.D.; Klimstra, D.; Paradis, V.; Rugge, M.; Schirmacher, P.; Washington, K.M.; Carneiro, F.; Cree, I.A. The 2019 WHO classification of tumours of the digestive system. Histopathology 2020, 76, 182-188. [CrossRef] [PubMed]

141. Phipps, A.I.; Buchanan, D.D.; Makar, K.W.; Win, A.K.; Baron, J.A.; Lindor, N.M.; Potter, J.D.; Newcomb, P.A. KRAS-mutation status in relation to colorectal cancer survival: The joint impact of correlated tumour markers. Br. J. Cancer 2013, 108, 1757-1764 [CrossRef]

142. O'Connor, J.M.; Sanchez Loria, F.; Ardiles, V.; Grondona, J.; Sanchez, P.; Andriani, O.; Fauda, M.; Brancato, F.; Huertas, E.; Alvarez F.; et al. Prognostic impact of K-RAS mutational status and primary tumor location in patients undergoing resection for colorectal cancer liver metastases: An update. Future Oncol. 2019, 15, 3149-3157. [CrossRef]

143. Díaz-Rubio, E.; Gómez-España, A.; Massutí, B.; Sastre, J.; Reboredo, M.; Manzano, J.L.; Rivera, F.; Safont, M.J.; Montagut, C.; González, E.; et al. Role of Kras status in patients with metastatic colorectal cancer receiving first-line chemotherapy plus bevacizumab: A TTD group cooperative study. PLoS ONE 2012, 7, e47345. [CrossRef]

144. Porru, M.; Pompili, L.; Caruso, C.; Biroccio, A.; Leonetti, C. Targeting KRAS in metastatic colorectal cancer: Current strategies and emerging opportunities. J. Exp. Clin. Cancer Res. 2018, 37, 57. [CrossRef]

145. Tan, C.; Du, X. KRAS mutation testing in metastatic colorectal cancer. World J. Gastroenterol. 2012, 18, 5171-5180. [CrossRef] [PubMed]

146. Hutchins, G.; Southward, K.; Handley, K.; Magill, L.; Beaumont, C.; Stahlschmidt, J.; Richman, S.; Chambers, P.; Seymour, M.; Kerr, D.; et al. Value of mismatch repair, KRAS, and BRAF mutations in predicting recurrence and benefits from chemotherapy in colorectal cancer. J. Clin. Oncol. Off. J. Am. Soc. Clin. Oncol. 2011, 29, 1261-1270. [CrossRef] [PubMed]

147. Andreyev, H.J.; Norman, A.R.; Cunningham, D.; Oates, J.; Dix, B.R.; Iacopetta, B.J.; Young, J.; Walsh, T.; Ward, R.; Hawkins, N.; et al. Kirsten ras mutations in patients with colorectal cancer: The 'RASCAL II' study. Br. J. Cancer 2001, 85, 692-696. [CrossRef] [PubMed]

148. Andreyev, H.J.; Norman, A.R.; Cunningham, D.; Oates, J.R.; Clarke, P.A. Kirsten ras mutations in patients with colorectal cancer: The multicenter "RASCAL" study. J. Natl. Cancer Inst. 1998, 90, 675-684. [CrossRef] [PubMed]

149. Yoon, H.H.; Tougeron, D.; Shi, Q.; Alberts, S.R.; Mahoney, M.R.; Nelson, G.D.; Nair, S.G.; Thibodeau, S.N.; Goldberg, R.M.; Sargent, D.J. KRAS codon 12 and 13 mutations in relation to disease-free survival in braf-wild-type stage III colon cancers from an adjuvant chemotherapy trial (n0147 alliance). Clin. Cancer Res. 2014, 20, 3033-3043. [CrossRef] [PubMed] 
150. Andersen, S.N.; Løvig, T.; Breivik, J.; Lund, E.; Gaudernack, G.; Meling, G.; Rognum, T. K-ras mutations and prognosis in large-bowel carcinomas. Scand. J. Gastroenterol. 1997, 32, 62-69. [CrossRef] [PubMed]

151. Bouzourene, H.; Gervaz, P.; Cerottini, J.-P.; Benhattar, J.; Chaubert, P.; Saraga, E.; Pampallona, S.; Bosman, F.; Givel, J.-C. p53 and Ki-ras as prognostic factors for Dukes' stage B colorectal cancer. Eur. J. Cancer 2000, 36, 1008-1015. [CrossRef]

152. Dinu, D.; Dobre, M.; Panaitescu, E.; Bîrlă, R.; Iosif, C.; Hoara, P.; Caragui, A.; Boeriu, M.; Constantinoiu, S.; Ardeleanu, C. Prognostic significance of KRAS gene mutations in colorectal cancer-preliminary study. J. Med. Life 2014, 7, 581.

153. Werling, R.W.; Yaziji, H.; Bacchi, C.E.; Gown, A.M. CDX2, a highly sensitive and specific marker of adenocarcinomas of intestinal origin: An immunohistochemical survey of 476 primary and metastatic carcinomas. Am. J. Surg. Pathol. 2003, 27, 303-310. [CrossRef]

154. Dalerba, P.; Sahoo, D.; Paik, S.; Guo, X.; Yothers, G.; Song, N.; Wilcox-Fogel, N.; Forgó, E.; Rajendran, P.S.; Miranda, S.P.; et al. CDX2 as a Prognostic Biomarker in Stage II and Stage III Colon Cancer. N. Engl. J. Med. 2016, 374, 211-222. [CrossRef]

155. Tomasello, G.; Barni, S.; Turati, L.; Ghidini, M.; Pezzica, E.; Passalacqua, R.; Petrelli, F. Association of CDX2 Expression with Survival in Early Colorectal Cancer: A Systematic Review and Meta-analysis. Clin. Colorectal Cancer 2018, 17, 97-103. [CrossRef]

156. Hansen, T.F.; Kjær-Frifeldt, S.; Eriksen, A.C.; Lindebjerg, J.; Jensen, L.H.; Sørensen, F.B.; Jakobsen, A. Prognostic impact of CDX2 in stage II colon cancer: Results from two nationwide cohorts. Br. J. Cancer 2018, 119, 1367-1373. [CrossRef] [PubMed]

157. Bruun, J.; Sveen, A.; Barros, R.; Eide, P.W.; Eilertsen, I.; Kolberg, M.; Pellinen, T.; David, L.; Svindland, A.; Kallioniemi, O. Prognostic, predictive, and pharmacogenomic assessments of CDX 2 refine stratification of colorectal cancer. Mol. Oncol. 2018, 12, 1639-1655. [CrossRef] [PubMed]

158. Slik, K.; Turkki, R.; Carpen, O.; Kurki, S.; Korkeila, E.; Sundstrom, J.; Pellinen, T. CDX2 Loss with Microsatellite Stable Phenotype Predicts Poor Clinical Outcome in Stage II Colorectal Carcinoma. Am. J. Surg. Pathol. 2019, 43, 1473-1482. [CrossRef] [PubMed]

159. Ribeirinho-Soares, S.; Padua, D.; Amaral, A.L.; Valentini, E.; Azevedo, D.; Marques, C.; Barros, R.; Macedo, F.; Mesquita, P.; Almeida, R. Prognostic significance of MUC2, CDX2 and SOX2 in stage II colorectal cancer patients. BMC Cancer 2021, 21, 359. [CrossRef] [PubMed]

160. Olsen, J.; Eiholm, S.; Kirkeby, L.T.; Espersen, M.L.; Jess, P.; Gögenür, I.; Olsen, J.; Troelsen, J.T. CDX2 downregulation is associated with poor differentiation and MMR deficiency in colon cancer. Exp. Mol. Pathol. 2016, 100, 59-66. [CrossRef] [PubMed]

161. Spano, J.P.; Lagorce, C.; Atlan, D.; Milano, G.; Domont, J.; Benamouzig, R.; Attar, A.; Benichou, J.; Martin, A.; Morere, J.F.; et al. Impact of EGFR expression on colorectal cancer patient prognosis and survival. Ann. Oncol. 2005, 16, 102-108. [CrossRef]

162. Bertotti, A.; Papp, E.; Jones, S.; Adleff, V.; Anagnostou, V.; Lupo, B.; Sausen, M.; Phallen, J.; Hruban, C.A.; Tokheim, C. The genomic landscape of response to EGFR blockade in colorectal cancer. Nature 2015, 526, 263-267. [CrossRef]

163. Van Emburgh, B.O.; Arena, S.; Siravegna, G.; Lazzari, L.; Crisafulli, G.; Corti, G.; Mussolin, B.; Baldi, F.; Buscarino, M.; Bartolini, A. Acquired RAS or EGFR mutations and duration of response to EGFR blockade in colorectal cancer. Nat. Commun. 2016, 7, 1-9. [CrossRef]

164. Arena, S.; Bellosillo, B.; Siravegna, G.; Martínez, A.; Cañadas, I.; Lazzari, L.; Ferruz, N.; Russo, M.; Misale, S.; González, I. Emergence of multiple EGFR extracellular mutations during cetuximab treatment in colorectal cancer. Clin. Cancer Res. 2015, 21, 2157-2166. [CrossRef] 